\title{
Experimental Treatment Options in Absence Epilepsy
}

\author{
Gilles van Luijtelaar ${ }^{1, *}$, Mehrnoush Zobeiri ${ }^{2}$, Annika Lüttjohann ${ }^{2}$ and Antoine Depaulis ${ }^{3,4,5}$
}

\begin{abstract}
${ }^{1}$ Biological Psychology, Donders Centre for Cognition, Radboud University, Nijmegen, The Netherlands; ${ }^{2}$ Institute of Physiology I, Westfälische Wilhelms Universität, D-48149 Münster, Germany; ${ }^{3}$ Inserm, U1216, F-38000 Grenoble, France; 4Univ. Grenoble Alpes, Grenoble Institut des Neurosciences, F-38000 Grenoble, France; ${ }^{5}$ CHU de Grenoble, Hopital Michallon, F-38000 Grenoble, France
\end{abstract}

\section{A R T I C L E H I S T O R Y}

Received: June 20, 2017

Accepted: October 12, 2017

DOI:

$10.2174 / 1381612823666171017170226$

\begin{abstract}
Background: The benign character of absence epilepsy compared to other genetic generalized epilepsy syndromes has often hampered the search for new treatment options. Absence epilepsy is most often treated with ethosuximide or valproic acid. However, both drugs are not always well tolerated or fail, and seizure freedom for a larger proportion of patients remains to be achieved. The availability of genuine animal models of epilepsy does allow to search for new treatment options not only for absence epilepsy perse but also for other genetic - previously called idiopathic - forms of epilepsy. The recent discovery of a highly excitable cortical zone in these models is considered as a new therapeutic target area.
\end{abstract}

Methods: Here, we provide an overview regarding the search for new therapeutical options as has been investigated in the genetic rodent models (mainly WAG/Rij and GAERS) including drugs and whether antiepileptogenesis can be achieved, various types of electrical and optogenetical invasive stimulations, different types of noninvasive stimulation and finally whether absence seizures can be predicted and prevented.

Results: Many factors determine either the cortical and or thalamic excitability or the interaction between cortex and thalamus and offer new possibilities for new anti-absence drugs, among others metabotropic glutamatergic positive and negative allosteric modulators. The inhibition of epileptogenesis by various drugs with its widespread consequences seems feasible, although its mechanisms remain obscure and seems different from the antiabsence action. Surgical intervention on the cortical zone initiating seizures, either with radiosurgery using synchrotron-generated microbeams, or ablation techniques might reduce spike-and-wave discharges in the rodent models. High frequency electrical subcortical or cortical stimulation might be a good way to abort ongoing spikeand-wave discharges. In addition, possibilities for prevention with real-time EEG analyses in combination with electrical stimulation could also be a way to fully control these seizures.

Conclusion: Although it is obvious that some of these treatment possibilities will not be used for absence epilepsy and/or need to be further developed, all can be considered as proof of principle and provide clear directives for further developments.

Keywords: ????????????

\section{INTRODUCTION}

Absence Epilepsy (AE) is characterized by generalized nonconvulsive seizures concomitant with a cessation of bodily activity and associated with a transient alteration of consciousness and responsiveness. Seizures in patients are often accompanied by mild automatisms or moderate clonic components affecting the limbs, eyeballs or eyelids [1]. Typical absence seizures are accompanied bybilateral symmetrical, synchronous and regular $3-\mathrm{Hz}$ spike-andwave discharges (SWDs) present on the electroencephalogram. Absence seizures start and end abruptly without any sign of postictal depression. They first occur around the age of 4-6 years and preferentially occur during periods of quiet wakefulness, inattention and preferably at transitions between awakening and sleep. In general, they last less than $10-20 \mathrm{sec}$ but may occur frequently in some patients. The pharmacological sensitivity of absence seizures is quite unique: they are suppressed by ethosuximide (ETX), which is not effective in most other forms of epilepsy [2] but also by some large-spectrum antiepileptic drugs (mainly valproate (VPA) and, to a lesser extent lamotrigine (LTG)) [3]. By contrast, they are aggravated by sodium channel blockers such as carbamazepine and phenytoin that are rather effective against generalized convulsive

*Address correspondence to this author at teh Biological Psychology, Donders Centre for Cognition, Radboud University, Nijmegen, the Netherlands; E-mail: g.vanLuijtelaar@donders.ru.nl and partial seizures [1]. AE patients generally do not present other neurological disorders, although cognitive and affective comorbidities have been described [4]. In typical childhood absence epilepsy, remission is observed during adolescence in about $70 \%$ of the patients [5].

\subsection{Genetic Rodent Modelsof Absence Epilepsy}

Our current knowledge on AE has been mainly achieved from experiments performed onanimal models and more specifically, genetic models in mice and rats (see [6,7] for recent reviews). The genetic background of absence seizures in these modelsprovidesa unique opportunity for studyingindividuals with a natural historyclose to clinical situations; an ideal condition to understand the pathophysiology of human AE and its evolution over life time [6]. Different genetic models have been described in mice and rats based on EEG recordings demonstrating the occurrence of spontaneous SWDs associated with behavioural arrest. Three main features confer to these models a considerable value in the understanding of AE: (i) the possibility to record SWDs regularly, over a lifetime period, in either, and preferably, freely moving or, when necessary, in immobilized animals; (ii) the comparison of data between epileptic and non-epileptic lines and, (iii) the possibility to explore epileptic animals before the onset of seizures. This is in particular the case in the two rat models which have been described and mostly studied: the WAG/Rij $[8,9]$ and the GAERS $[10,11]$ strains. The fully developed SWDs are present in all GAERS at 30 days 
postnatal $[12,13]$ and in $80 \%$ of the 3-month old WAG/Rij individuals [14], for a head to head comparison between WAG/Rij's and GAERS rats see [15]. In all genetic models of AE, animals exhibit bilateral and synchronized SWDs that start and end abruptly [6]. As in human patients, there is no postictal depression. These SWDs have a frequency between $5-9 \mathrm{~Hz}$ and a duration of 1 to $60 \mathrm{~s}$ in the mice and rat models. The recurrence of SWDs can vary from 1 to 260 SWDs per hour, depending on the model, the age of the animals and the recording conditions. The spike frequency is generally higher at the beginning of a SWD (up to $11 \mathrm{~Hz}$ in rat models) whereas a frequency of about $7-9 \mathrm{~Hz}$ is observed one-two seconds after its beginning and for the rest of the discharge [10, 16-20]. This may reflect the dynamics in firingpattern of neurons underlying SWDs and suggests that different circuits may be rapidly recruited within the first few seconds of SWDs [21]. Similar frequency dynamics have been found in people with AE [20].

\subsection{How Animal Models of Absence Epilepsy can Help Devel- oping Innovative Therapeutic Strategies}

The excellent pharmacological predictivity of the two rat models, as well as the steady occurrence of SWDs over extended periods of time, make them models of choice to develop and evaluate new and innovative therapies for the epilepsies ${ }^{11]}$. These new treatment options are not developed for invasive treatment of $\mathrm{AE}$ per se, as this form of epilepsy remains relatively benign compared to other syndromes and because absence seizures are generally reasonably well controlled by several antiepileptic drugs (see later). However, the recent identification of a highly excitable cortical "focus" triggering and generating spontaneous SWDs [19,22] offers a novel opportunity to show proofs of concept for innovative targeted strategies.

The initial work inWAG/Rijbased on cortico-cortical and cortico-thalamic network analyses (non-linear association strength) strongly suggested that SWDs are initiated in the somatosensory cortex (SoCx) [23]. Since then, the initiating role of this cortical region was confirmed and further explored in WAG/Rij [2433], GAERS [19,34-38], Long-Evans rats with spontaneous occurring SWDs $[39,40]$ and in mice with a juvenile myoclonic epilepsy mutation (Gabra1[A322D]) exhibiting both absence and myoclonic generalized seizures [41]. Studying the association strength between field potentials recorded from cortical and thalamic regionsin freely moving GAERS also suggested the facial SoCx, or barrel cortex, as an origin for the initiation of SWDs [35]. In addition, short $(1-2 \mathrm{sec})$ SWDs were recorded in this cortical area that did not spread to other regions, whereas the reverse was never observed [19]. These findings along with fMRI data and focal pharmacological manipulations from the rodent models, demonstrated that 'SWDs are initiated in the facial SoCx and that an intracortical propagation of ictal activity appears as the mechanism of primary generalization of spontaneous occurring SWDs' [22]. The concept of a cortical initiation zone for SWDs is in line with the outcomes of high density EEG and MEG studies revealinga role of the frontal cortex in initiation of SWDs in AE patients $[42,43]$.The identification of the SoCx as the site of SWDs initiation has allowed to start deciphering the cellular mechanisms underlyingSWDs in GAERSby in vivo intracellular electrophysiological recordings. It was shown for instance that the 'occurrence of spike-wave activity on the surface EEG of SoCx is correlated withthe corresponding deep-layer pyramidal neurons which exhibit suprathreshold rhythmic depolarizations' with accompanying action potentials, superimposed on a tonic membrane hyperpolarization that lasts throughout the SWD [19,36,37]. This increase in cell polarization observed in cortical neurons during SWDs differs from the classical sustained depolarizing shift found in other forms of seizures. Moreover, the 'mean firing rate of cortical neurons in GAERS during SWDs is not changed compared to the preceding quiescent periods, even in the ictogenic neurons. Cortical neurons during seizures may not systematically generate "paroxysmal" discharges and absence seizures may rather be associated with a change in the temporal pattern of neuronal firing [11].

These findings support the hypothesis that 'SWDs primarily originate from aberrant activity of pyramidal neurons located in the deep layers of SoCx. This activity associates an excessively depolarized membrane potential together with an elevated and highly regular spontaneous firing during interictal periods, with rhythmic brisk discharges during SWDs that precede and exceed the firing of distant cortical and thalamic neurons'. It may suggest that specific molecular alterations exist in cortical neurons [11]. For instance, in vitro experiments in the $\mathrm{WAG} / \mathrm{Rij}$ suggest that dysregulation of hyperpolarization- activated current $\left(\mathrm{I}_{\mathrm{h}}\right)$, the pacemaker current carried by hyperpolarization-activated cyclic nucleotide-gated potassium channels $(\mathrm{HCN})$, may promote epileptogenesis andstabilizes the HCN channels function through compensatory mechanisms. It may also be invoved in the termination of SWDs [44]. Its cortical origin, as well as the underlyingpathophysiological mechanismsremain to be examined in other models of AE.

\section{NEW ANTI-ABSENCE DRUGS?}

Little progress has been made regarding the development of new anti-absence drugs during the last 20 years. Indeed, the most prevalent anti-absence medications, ETX and VPA, have been used for the last 50-60 years and only LTG, which has been introduced in the 1990's, is used currently on a relatively large scale as monotherapy. An open-label, randomized, parallel-group study comparing head-to-head the efficacy of VPA and LTG in newly diagnosed children and adolescents with typical absence seizures during one year showed that the efficacy of VPA was superior after 1 months. At 3 and 12 months the differences were no longer significant, althoughmore patients taking VPA achieved seizure freedom than did those taking LTG [45]. Zonisamide (ZNS) approved for adjunctive treatment of partial seizures in adults, has also been investigated in a group of 45 children and adolescents with absence epilepsy and about $49 \%$ of them became seizure free [46]. ZNS is not recommended due to its slow onset and chances of adverse effects and thatother antiabsence drugs have a better safety and efficacy profile. Theshort (2 weeks) term efficacy of levetiracetam (LEV) was established in a randomized double-blind parallelgroupplacebo-controlled design. The outcomes showed that this compound was superior to placebo in suppressing absences [47]. However, the responder rates were modest.

The differences in efficacy among the three first-line antiabsence drugs have become clear from a large randomized double blind multicenter clinical trial of initial therapy, aiming to compare different aspects of ETX, VPA and LTG. ETX and VPA wereidentified as drugs with superior efficacy compared to LTG. However, ETX was identified asthe optimal initial therapy since it had fewer attentional adverse effects when compared to VPA $[3,48]$. The higher efficacy of ETX and VPA in comparison toLTG was confirmed by others [49], also as a second monotherapy [50]. Berg et al. (2014) proposed that ETX might have a disease-modifying effect and a high remission rate [5]. In addition, children who were succesfully treated with ETX as the first medication, had a particular low risk of developing subsequent generalized tonic clonic seizures [51]. Despite these rather favorable outcomes for ETX, therapy with this drug was found to fail in $47 \%$ of subjects due to seizures, intolerable side-effects oreven withdrawal from the study [2]. Epidemiologic cohort studies showed only seizure freedom in the range from $21 \%-74 \%{ }^{2}$. In five prospective cohort studies, the proportion of seizure free subjects was $57 \%-74 \%$. An Italian multicentre study showed that $49 \%$ of their cohort of drug resistant absence patients did not become seizure free even after 3 or 4 types of antiepileptic drugs during a 3-year follow up study[52]. Although "AE is labeled as a "benign" syndrome, its clinical course is variable and remission rates are far lower than in other classic benign genetic epilepsies such as Benign Rolandic Epilepsy'[2]. All this 
implies that there is ample room for new and better anti-absence drugs that should be compared with the current optimal initial standard, ETX.

Interestingly, a better usage of the existing drugs can be made: afavorable drug response to ETX and VPA can be predicted with a high sensitivity and specificity. This prediction is based on spectral density of the peak frequency of the first $2 \mathrm{~s}$ of SWDs. Other factors that might have played a role in drug response in AE patients, such as type of drug, age of onset, type of syndrome (juvenile absence epilepsy or childhood AE) did not predict a favorable outcome, although some of these factors might be underpowered [53]. A second way to predict favorable drug responses determined 16-20 weeks after the initiation of treatment (ETX and LTG) is based on the identification of polymorphism of the T-type $\mathrm{Ca}^{2+}$ channel genes CACNA1G, CACNA1H, and CACNA1I, involved in the pathological absence networkand of the ABCB1 transporter gene which codes for P-glycoprotein, a drug efflux transporter [54]. It acts at the membrane of brain capillary endothelial cells and is relevant for the action of LTG. It was found that the presence of either a CACNA1H or a CACNA1I missensevariant was more often associated with lack of response to ETX and that an ABCB1 missense polymorphism was less, whereas two CACNA1H polymorphisms were more common in good responders to LTG. The authors conclude that "prospects are bright for integrated genetic/nonheritable precision medicine therapies for children with CAE [54]".

\subsection{A Bag Full of Possibilities and Challenges}

In principle,there is an unlimited number of ways to manipulate the occurrence of SWDs, among them the classical neurotransmitters that modulate the activity of cortico-thalamo-cortical oscillations (C-T-C) (for recent reviews see [55-57]). Anti-inflammatory drugs might also be putative candidates as antiepileptic drugs [58], including absence epilepsy [59]. For example, the selective COX-2 inhibitor etoricoxib, which inhibits the production of proinflammatory prostaglandins, suppresses SWDs, although not to a large extent [60]. In addition, signaling pathways are getting more and more attention. In particular, it was shown that inhibition of themammalian target for rapamycin (mTOR), a regulator of different cellular processes, reduced number and mean duration of SWDs when administered acutely or sub-chronically [61]. Also, ion channel modulators such as (-)BRL34915, an active isomer of a $\mathrm{K}^{+}$ channel opener, reduced SWDs in WAG/Rij rats [62]. Compounds thatselectively target the upregulated genes for channel Nav1.1 and Nav1.6 in the SoCx [25] might be suitable targets in AE genetic models. Relevant for this is that phenytoin, an antiepileptic drug known to enhance SWDs in absence patients and in the genetic models, reduces SWDs when administered in the cortical initiating zone [63]. HCN channels and their subtypes 1,2, and 4 expressed in cortex and thalamus appear to be involved in SWD occurrence in genetic models $[64,65]$. Yet, there are only a few selective pharmacological agents such as MEL57A and EC-18 for HCN1 and HCN4 respectively that target the different subtypes [66]. However, they await being evaluated in the genetic models. A single preliminary study showed that the $\mathrm{I}_{\mathrm{h}}$ blocker ORG 34167, which has a high affinity for the HCN1 receptor, suppressed SWDs in WAG/Rij rats. The drug prolonged also the duration of wakefulness characterized by a desynchronized EEG and passive behavior [67]. The cannabinoid system modulates SWDs, as was suggested by the use of $\mathrm{R}(+)$ WIN55212-2, a CB1 receptor agonist. R(+)WIN55212-2dosedependently reduced the incidence of SWDs in the first $3 \mathrm{~h}$ after injection, and this was followed by an increase in the mean SWD duration, suggesting a biphasic modulation of SWDs by this agonist. Both effects were reversed or attenuated when the agonist was combined with the antagonist AM251 [68]. In agreement, the synthetic CB1 receptor antagonist/inverse agonist SR141716 enhanced SWDs [69].
Astrocyte-modulating approaches, in particular via the use of the glial modulating agent ONO-2506, have been shown to controlnon-convulsive forms of epilepsy in genetic mice model of absence epilepsy (Cacna1a(tm2Nobs/tm2Nobs), as it reduced both the number and mean duration of SWDs dose-dependently [70]. Similarly, gap junction blockers were suppressive, in line with the hypothesis that neurons of the reticular nucleus of the thalamus (RTN) contribute to synchronization necessary for the hyper synchrony of the thalamo-cortical network during SWD [71]. Adenosine might also play a role in $\mathrm{AE}$ after it was established that non-selective A1R/A2R antagonists reduce SWDs [72] and that the receptor density of excitatory $\mathrm{A}(2 \mathrm{~A}) \mathrm{R}$ was lower in 2 month (presymptomatic) WAG/Rij rats when compared toaged matched control rats. Accordingly, $\mathrm{A}(2 \mathrm{~A}) \mathrm{R}$ stimulation ofcortico-thalamicbrain slices from the young WAG/Rij rats, with the agonist 2-[4-(-2-carboxyethyl)phenylamino]-5'-N-ethylcarboxamido-adenosine failed to modulate either cAMP formation, mitogen-activated protein kinase system, or $\mathrm{K}\left({ }^{+}\right)$-evoked glutamate release. In contrast, compared to the control animals, symptomatic WAG/Rij rats showed a significant increase in the expression of $\mathrm{A}(2 \mathrm{~A}) \mathrm{R}$, receptor signaling and function. Application ofthe 2AR antagonist SCH58261 reduced the number and mean duration of SWDs, regardless of whether the drug was administered in cortex, thalamus or systemically. It was suggested that SCH58261 is effective in preventing absence seizures by blocking the facilitatory $\mathrm{A}(2 \mathrm{~A}) \mathrm{R}$ activity, which may contribute to the triggering/maintenance of SWD [73].

The mechanism of action of LEVis based on the synaptic vesicle protein named 2A (SV2A). This protein is ubiquitously expressed in the brain and SV2A knockout mice were shown to develop a strong seizure phenotype. It was predicted that LEV might act on absences as well. When tested in either GAERS [74] or WAG/Rijrats [75] LEV was found effective in suppressing SWDs. Later, a similar suppressive effect was reported in AE patients [76] supporting the hypothesis that SV2A ligands have anti-absence effects. Finally, Neuropeptide $\mathrm{Y}$ has been found to be a modulator of SWDs: its presence on GABA-ergic cells of the RTN and the cerebral cortex makes it a suitable candidate. NPY signaling isthrough Y1, Y2, Y4, and Y5 G-protein-coupled receptors andactivation of these receptors inhibits adenylate cyclase and decrease intracellular $\mathrm{Ca}^{2+}$ [77]. In GAERS, local application in the SoCx of NPY reduces SWDs, whereas its administration in the ventral basal complex of the thalamus increases them [78].

\subsection{New T-Type Calcium Channel Blockers}

The mechanism of action of the classical prototype of a T-type $\mathrm{Ca}^{2+}$ blocker, ETX, was revealed 30 years ago [79]. Coulter and coworkers showed that ETX blocks the T-type voltage-gated $\mathrm{Ca}^{2+}$ channel in thalamo-cortical neurons and reduced burst firing, although other mechanisms have been found since then [80-84]. ETX appears particularly effectivewhen applied in the SoCx, as established in GAERS, where it reduces the excitability of highly excitable subgranular pyramidal cortico-thalamic cells [11, 35, 85].In fact, ETX normalized the behaviour of these cells and by doing this, SWDs no longer occurred. This outcome suggests that a putative new drug for AE should be evaluated for its efficacy not only after systemic administration, but also for its action in SoCx. Novel Ttype $\mathrm{Ca}^{2+}$ channel antagonists were tested in animal models [86] and in vivo assessment of two of them (Z941 and Z944), showed that both compounds suppressed incidence and mean duration of SWDs in GAERS more potently and by a mechanism distinct from that of ETX [87]. In the meantime, Z944 has entered clinical stage II, but as an analgesic. A new series of $\mathrm{Ca}^{2+}$ channel blockers withrelativelygood oral bioavailability and brain penetration across species, showed a robust reduction in the number and duration of SWDs with no cardiovascular effects in the WAG/Rijmodel [88]. It is not known whether these latter drugs will be further developed as anti-absence drugs. 
New anti-absence drugs might also target glutamatergic and/or GABA-ergic neurotransmission, the most relevant neurotransmitters in the C-T-C network involved in the oscillations responsible for the highly characteristic SWDs. Here, we concentrate on mGluR, considering that the work in absence models has shed a different light on the existing literature regarding the role of glutamate on epilepsy.

\subsection{MGlureceptors}

The discovery of metabotropic glutamate receptors (mGluRs) at pre- and postsynaptic GABA-ergic and glutamatergic neurons and consequently their presence within the C-T-C circuit opened new vistas for the investigation of new anti-absence drugs [89]. Moreover, targeting mGluRs might be less toxic than targeting ionotropic GluRs. Allosteric modulators have been shown to be safer than orthosteric modulators and already have entered clinical trials for other neurological and psychiatric disorders [90]. Finally, drugs binding to mGluR do exert pro- or anti-epileptic effects in various seizure and epilepsy models, so the roles as putative antiepileptic drugs deserves to be explored [91].

Based on amino acid sequences, pharmacologic profile, and Gprotein coupling profile, mGlu receptors are subdivided into three groups with 8 subtypes [92]. Group I consists ofmGlu1 and mGlu5 receptors, which are coupled to Gq proteins. Activation of these receptorstriggers the hydrolysis ofpolyphosphoinositide and formation of inositol-1,4,5-trisphosphate and diacylglycerol. MGlu1 and mGlu5 receptors also control the activity of various types of $\mathrm{Ca}^{2+}$ and $\mathrm{K}^{+}$channels [93]. Group II receptors (mGlu2 and mGlu3 respectively), which are coupled to Gi/Go proteins, negatively modulate the activity of adenyl cyclase and voltage-sensitive $\mathrm{Ca}^{2+}$ channels (VSCCs). Group III consists of mGlu4, mGlu6, mGlu7, and mGlu8 receptors, which are also coupled to Gi/Go proteins. The availability of selective orthosteric and even more important selective positive and negative allosteric modulators (PAMs and NAMs) will give new opportunities to investigate compounds for their possible anti-absence action. Here the results of studies with the WAG/Rij model will be discussed.

Group I: The roles of group I mGlu receptors-both mGlu1 and mGlu5 were investigated. These receptors are mostly expressed in the peripheral portion of the postsynaptic density, where they cause excitatory responses and control synaptic plasticity [94]. The expression and signaling of mGlul receptors was reduced in the thalamus of WAG/Rij rats when compared to aged matched nonepileptic control rats. The mGlu1 NAM, JNJ16259685 showed a dose-dependent increase in the number of SWDs, while the mGlu1 PAM, RO0711401 decreased dose and time dependently the number of SWD. It is possible that the effects of this PAM on number and duration of SWDsin WAG/Rij rats are caused by hypo-function of mGlu1 receptors in the thalamus. We have proposed that this PAM should be further developed as an anti-absence drug in particular, although at forehand it is surprising that a drug known to increase glutamatergic neurotransmission reduces SWDs [94].

WAG/Rij ratsshowed a decrease in both the mGlu5 receptor protein levels and receptor function in the thalamus when compared to age-matched non-epileptic ACI (Agouti-Copenhague Irish) rats. In contrast, the expression of mGlu5R was enhanced in the motor and $\mathrm{SoCx}$ without an accompanying change in mGlu5-receptor function [95]. The pharmacological studies showed that the selective mGlu1R PAM, VU0360172, significantly reduced SWDs, without affecting motor behavior. Importantly, the effects of this PAM were prevented by co-treatment with the selective antagonist MTEP. This may indicate that the PAM decreased SWDs by amplifying the endogenous activation of mGlu5R. Whether these pharmacological effects are due to a hypo-functional thalamus as was found in WAG/Rij rats remains to be answered by testing the compound in other genetic models that do not show this hypofunctional thalamus.
Antiepileptic drugs have to be chronically administered and therefore it was subsequently investigated whether RO0711401 and VU0360172 develop tolerance [96]. WAG/Rij rats were injected twice daily for 10 consecutive days. Rats quickly (on the third day) developed tolerance to RO0711401. In contrast, VU0360172 kept its anti- absence activity (Fig. 1).

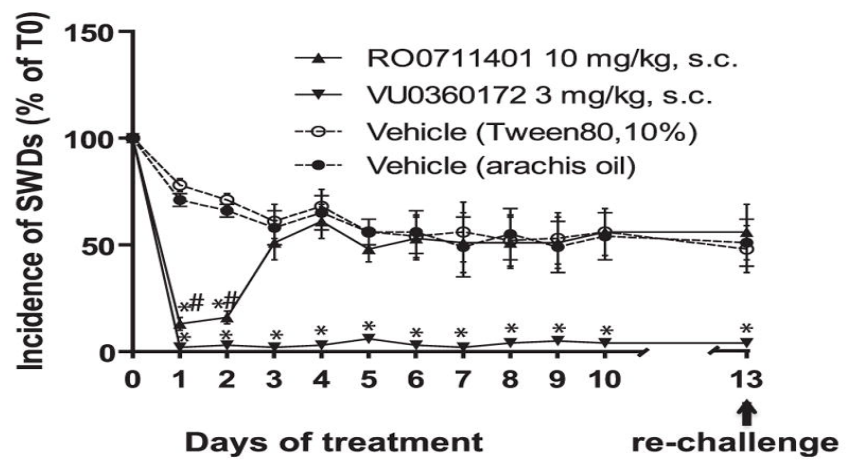

Fig. (1). Effects of sub chronic (10 days, twice-daily s.c.) administration of Group I PAMS (RO0711401, $10 \mathrm{mg} / \mathrm{kg}$ and VU0360172, $3 \mathrm{mg} / \mathrm{kg}$ ) and their respective vehicles. Tolerance developed for the anti-absence activity of RO0711401 at the $3^{\text {rd }}$ day of treatment, VU0360172 seemed devoid of tolerance. A rechallenge with each of the two drugs was performed after 2 days of withdrawal. The incidence of SWDs at $1 \mathrm{~h}$ after the morning injection is shown. Values are Mean \pm S.E.M. $\mathrm{P}<0.05$ vs. the respective vehicles. (adapted after [96])

Group II. Only two studiesaddressed the role of Group II mGluR. Six-month-old symptomatic WAG/Rijrats showed an increased expression of mGlu2/3 R's in the ventrolateral regions of the SoCx, ventrobasal thalamus, and hippocampus, but not in RTN as assessed by immunohistochemistry and western blotting compared to presymptomatic so young WAG/Rij and to non-epileptic control rats. In contrast, $\mathrm{mGlu} 2 / 3$ receptor signaling was reduced in the SoCx. It was proposed that 'upregulation of these receptors in the SoCx might be involved in the pathogenesis of absence epilepsy'. The orthosteric mGlu2/3 receptor agonist LY379268 dosedependently increased the number of SWDs during 3-7 h posttreatment, whereas the orthosteric antagonist LY341495 dosedependent reduced its number [97]. However, studies in $\mathrm{lh} / \mathrm{lh}$ mice with the same mGlu2/3 receptor agonist (LY379268) showed an opposite effect, i.e., a decrease in SWD incidence.Altogether, mGlu2/3 receptors appear to beinvolved in the generation of SWDs and an upregulation of these receptors in the SoCx might contribute to the pathogenesis of absence epilepsy [89].

Group III. Very little has been done regarding receptors in this group; here we briefly mention what has been done with the mGlu4 and mGlu8 receptors. MGlu8Rs are present at glutamatergic cortico-thalamic synapses innervating RTNand TC neurons. In intact cortico-thalamic slices, group III mGluR activation by the selective orthosteric agonist 1-AP4 suppressed evoked cortico-RTN responses. This was due to presynaptic suppression of glutamate release at the cortico-RT synapses via activation of autoreceptors. Indeed, selective activation of mGlu8R was sufficient to reduce cortico-RT synaptic release [98], and to dampen thalamic oscillations. Consequently, this action predicts that in vivo, SWD activity should be reducedby mGlu8R activation. The role of mGlu4R was investigated in WAG/Rij rats where its expression was enhanced in the RTN [99]. Electron microscopy and in situ hybridization data suggested that mGlu4 receptors in the RTN are localized on excitatory cortical afferents, confirming their role as autoreceptors. The presence of mGluR4 within RTN is therefore critical to GABAergic modulation of thalamo-cortical synchronization in normal and pathological oscillations (absence seizures). This and the work of 
Kyuyoung and Huguenard [98] supports the hypothesis that activation of mGlu4 receptors may inhibit the release of glutamate in the RTN, reduces the role of the RTN in inhibiting of TC cells and also bursting. Therefore, PAMs of this group should reduce SWDs. In contrast with this hypothesis, we found that systemic injection of the selective mGlu4R PAM PHCCC, substantially enhanced the number of SWDs in WAG/Rij rats [100]. This wasin line with an increase in absence-like seizures in PTZ-treated mice, whereas PHCCC was inactive in mGlu4 receptor knockout mice; these animals were 'intrinsically resistant to PTZ-induced absence seizures' [91]. Selective stimulation and local injection studies with selective PAMs and NAMS in cortex and thalamus should clarify the role of group III mGluRs.

\section{ABSENCE EPILEPSY EPILEPTOGENESIS.....}

The identification of a specific cortical region triggering SWDs in genetic rodent models of AE (see above), has recently instigated studies addressing the question whether the different characteristics of ictogenic neurons already exist at birth or progressively develop during brain maturation. This question is critical to design prophylactic treatments capable of interrupting $\mathrm{AE}$ epileptogenesis. In rodent models of $\mathrm{AE}$, the age of onset of the first SWDs varies from 25 to 120 days postnatal [6]. In WAG/Rij rats the early developmental changes in the focal zone have not been studied in such details. However, at 3.5 months of age, $85 \%$ of the WAG/Rij's have fully developed SWDs [14]. Two recent studies performed in GAERS rats and $\mathrm{C} 3 \mathrm{H} / \mathrm{HeJ}$ mice $[13,101]$ have shown that SWDs progressively mature during the first three weeks postnatal. Although age windows are slightly different between these two strains, three similar stages clearly describe the course of epileptogenesis. The first stage is characterized by "oscillatory discharges", composed ofirregular narrow spikes and no apparent waves. In both models, these discharges are rare, have a frequency around $5 \mathrm{~Hz}$ without harmonics and are concomitant with behavioral arrest [13]. They first appear around P15 in GAERS and P5 in $\mathrm{C} 3 \mathrm{H} / \mathrm{HeJ}$ mice [101]. They are not found in age-matched non-epileptic controls, suggesting that they are specific to AE epileptogenesis and could represent a related rhythmic brain activity of AE [13,101]. The second stage is characterized by the occurrence of SWDs mixed with the oscillatory discharges. These mixed discharges are first observed around P25 in GAERS and P15 in C3H/HeJmice. In GAERS, the proportion of SWDs increases as a function of age, although they represent less than $50 \%$ of events at this stage. Acute injection of VPA suppressed both oscillations and SWDs at this stage, suggesting that both patterns are epileptiform and may reflect a maturational process of SWDs [13]. After P30 in both models, the discharges are composed of a greater proportion of SWDs and an increase in discharge frequency reaching $8-9 \mathrm{~Hz}[13,101]$. This age in these two rodent modelscorresponds well to the age at which AE is generally diagnosed in patients [102]. Using in vivo intracellular electrophysiological recordings of deep layer pyramidal neurons in adult rats, it was recently demonstrated [13] that this maturation of cortical discharges in GAERS is accompanied by a progressive increase in the intrinsic excitability and synaptic drive of cortical neurons. This should lead to an enhanced ability of SoCx networks to generate synchronized oscillations and paroxysmal episodes. These data suggest that SoCx neuronal network can maturate differently in epileptic animals, leading to an abnormal functional and structural organization that facilitates neuronal hyperactivity and hypersynchronization. These changes occur in the rat at a period of cortical maturation which has been shown to be critical for the development of functional networks in the SoCx $[102,103]$. Molecular mechanisms involved in this functional development may therefore be key players in the pathophysiology of AE. Long-term changes in cortico-cortical, cortico-thalamic and subcortical networks in WAG/Rij and GAERS rats were also described even at rest and epileptogenesis is probably not restricted to the $\mathrm{SoCx}$ and its C-T-C network [29, 104, 105].

\section{1.......and Antiepileptogenesis}

In an attempt to develop curative rather than symptomatic treatment ETX or VPA were given chronically in GAERS from the age of 5 days up to 25 days postnatal, i.e., during the critical period of epileptogenesis when SWDs are not fully matured(see above). However, such treatment hadno consequences on the recurrence of these seizures later on, when the animals were adults, nor change the efficacyof these drugs to suppress SWDs [13]. This suggests that, at least in this model, antiepileptic drugs are not effective in impairing epileptogenesis despite the fact that when acutely administeredthey cansuppress immature SWDs (see also [11]). In WAG/Rij, 4-month pharmacological treatment with ETX initiated immediately after weaning, i.e., before SWDs onset, suppressed seizures several weeks after treatment was stopped [106]: the agedependent increase in SWDswasdelayed or even prevented, suggesting "antiepileptogenesis". Theseinitial results were replicated several times [32,107-109] and similar effects were also found in GAERS using the same protocol [110]. Initially, it was thought that the molecular changes due to epileptogenesis and antiepileptogenesis were restricted to the initiation site of SWDs [106]. Recently, it was shownthat changes in white matter, REM sleep, behaviour and network activityalso occur as a consequence of epileptogenesis and are "normalized" after a treatment leading to "antiepileptogenesis" [32, 107, 111]. However, it must be noted that a 2-month treatment with ETX either initiatedat weaning or 2 month later (instead of the 4-month periodwhich was previously used), was not sufficient to reduce SWDs and modify behavior [32]. Russo and colleagues (for review see [56]) investigated the antiepileptogenic effects of different compounds, not necessarily antiepileptic ones, onWAG/Rij rats with drug administration via drinking water from weaning to 5-6 months of age. Some of these drugs have, when acutely administered, a proabsence action (carbamazepine, CBZ and vigabatrin, VGA) or a weak antiabsence action (LTG), or no anti-absence action (Perampanel, PER), in contrast to ETX [112]. Among the treatments with different antiepileptic drugs, LEV had mild effects, CBZ no effects and VGA had clear antiepileptogenic effects. The latter was surprising, since this compound and other GABAmimetic drugs increase SWDs in animal models and AE patients [113]. The antiepileptic drug PER, a selective noncompetitive AMPA-receptor antagonist, approved for e.g. adjunctive treatment of focal and primarily generalized tonic-clonic seizures, temporarily suppressed SWDs after withdrawal [114]. These results show that mechanisms involved in antiepileptogenesis are different from mechanisms responsible for the acute SWD suppressing effects. The putative antiepileptogenic actions of psychoactive drugs were additionally explored. Both theselective serotonin reuptake blocker fluoxetine and the dual-acting serotonin-noradrenalin reuptake inhibitor duloxetinereduced SWDs, lower doses were not effective [56]. Three antipsychotic drugs haloperidol, risperidone and quetiapine were not effective either, while three different statins, atorvastatin, simvastatin, and pravastatin, known for their neuroprotective and anti-inflammatory effects, decreased SWDs (mild to large effects). In addition, rapamycin (RAP) delayed the development of SWDs in adult WAG/Rij rats, suggesting the involvement of the mTOR pathway [61], similar to what was found in other forms of epilepsy (e.g., lithium pilocarpine model of mesial temporal lobe epilepsy) in epileptogenesis [114]. As emphasized by these authors, chronic treatment only temporarily"suspended" the agedependent increase in SWD incidence. This implies that genuine and complete antiepileptogenesis has not been described yet in rodent models. This seems in contrast to what has been found in children with AE: in a retrospective clinical study, ETX was found to be associated with a high rate of complete remission [5]. Spontaneous remission and or a transition to more severeforms of genetic generalized epilepsy [51] were never reported in any genetic model of AE. This seems to be a real difference between the rodent models and clinical conditions. Such difference has to be taken into account when developing antiepileptogenesis treatments. In a dif- 
ferent approach WAG/Rij pups were treated from postnatal day 8 to 21 with the antidepressant clomipramine twice daily [115]. This treatment decreased SWDs once the rats were 8-month old, while REM sleep was enhanced. This suggests that early interventions may have long lasting permanent effects on SWDs but also on sleep regulating mechanisms.

\subsection{Subcortical Stimulation}

High-frequency stimulation of a number of deep brain structures has been proposed as a way to control epileptic seizures when other therapies (AED, surgical ablation, vagal nerve stimulation) fail or are not possible $[116,117]$. Clinical trials of DBS in refractory epilepsy patients using continuous or intermittent stimulation protocols have yielded encouraging results $[118,119]$. However, AE patients were never studied. High-frequency stimulation of the sub-thalamic nucleus was first shown to suppress SWDs in GAERS [120]. The idea to stimulate here came from studies on the role of the basal ganglia in the control of epileptic seizures [121, 122]. The optimal target was later found to be the substantia nigra reticulata, the main output station of the basal ganglia, and the optimal frequency to interrupt SWDs was $60 \mathrm{~Hz}$ [123]. However, these studies also revealed that open loop or 'continuous stimulation of these structures rapidly lead to a lack of response, probably due to a refractory period after each single stimulation'. Therefore,closed loop stimulation protocols, in which electrical stimulation will be triggered by seizure onset detected in real-time by the analyses of the ongoing EEG signals might be more appropriate [124-128], in particular when the seizure occurrence is high. It is obvious that this is indeed the casein the genetic animal models and inunmedicated AE patients. Closed loop stimulation presents three putative advantages for clinical use when compared to open loop continuous DBS: (i) less habituation and neural adaptation to stimulation; (ii) less behavioural or physiological unwanted-effects; (iii)more power saving and longer life for the batteries of the brain stimulators. An overview of the major stimulation studies in the genetic models and in rats with spontaneous SWDs is presented in Table $\mathbf{I}$.

Table I. Overview of electrical and optogenetic stimulation studies in the genetic absence models and in rats with absence seizures.

\begin{tabular}{|c|c|c|c|c|c|}
\hline Author (year) & $\begin{array}{l}\text { Model or type of } \\
\text { epilepsy }\end{array}$ & Type of stimulation & Stimulation site & $\begin{array}{l}\text { Frequency and dura- } \\
\text { tion of session }\end{array}$ & Outcome \\
\hline $\begin{array}{l}\text { Vercueil et al., } \\
1998\end{array}$ & GAERS & $\begin{array}{l}5 \text { sec bilateral high frequency stimula- } \\
\text { tion }(130 \mathrm{~Hz})\end{array}$ & Subthalamic nucleus & $\begin{array}{l}\text { At least } 10 \text { consecutive } \\
\text { SWD }\end{array}$ & $\begin{array}{l}\text { Disruption of SWD with intensities } \\
\text { that do not induce motor responses }\end{array}$ \\
\hline $\begin{array}{l}\text { Feddersen et al., } \\
\qquad 2007\end{array}$ & GAERS & $\begin{array}{l}5 \text { sec stimulation with various modes } \\
\text { (referential vs bipolar; monophasic vs } \\
\text { biphasic; unilateral vs bilateral) and } \\
\text { parameters (pulse width, frequency) to } \\
\text { obtainoptimal stimulation parameters }\end{array}$ & $\begin{array}{l}\text { Substantia nigra pars } \\
\text { reticulata }\end{array}$ & $40 \mathrm{~min}$ & $\begin{array}{l}\text { a) Optimal suppression of SWD with } \\
\text { least side effects and lowest intensity: } \\
\text { bilateral, bipolar, monophasic } 60 \mathrm{~Hz} \\
\text { b) } 50 \% \text { of non-interrupted SWD } \\
\text { occurred shortly following a former } \\
\text { interrupted SWD suggesting a refrac- } \\
\text { tory period }\end{array}$ \\
\hline $\begin{array}{l}\text { Liang et al., } 2010 \\
\text { Liang et al., } 2011\end{array}$ & $\begin{array}{c}\text { Long-Evans rats with } \\
\text { generalized absence } \\
\text { seizures }\end{array}$ & $\begin{array}{l}\text { Closed-loop stimulation by automated } \\
\text { BCI system, single pulse train of } \\
800 \mathrm{~Hz}, 30-40 \mu \mathrm{A} \text { and } 0.5 \mathrm{sec} \text { pulse } \\
\text { train duration }\end{array}$ & Zona incerta & $\begin{array}{l}2 \mathrm{~h} \text { during light phase } \\
\text { and } \\
2 \mathrm{~h} \text { during dark phase }\end{array}$ & $\begin{array}{c}90 \% \text { of SWD disrupted by stimulation, } \\
\text { detection delay time less than } .6 \mathrm{sec}\end{array}$ \\
\hline Saillet et al., 2013 & GAERS & $\begin{array}{l}\text { a) Closed-loop bilateral, } 2 \mathrm{sec} \text {, mono- } \\
\text { phasic, } 60 \mathrm{~Hz} \text { with different minimal } \\
\text { inter stimulation intervals (ISI) to } \\
\text { determine length of refractory period } \\
\text { b) Closed-loop, bilateral, } 2 \mathrm{sec} \text { mono- } \\
\text { phasic, } 60 \mathrm{~Hz} \text { stimulation, ISI } 60 \mathrm{sec}\end{array}$ & $\begin{array}{l}\text { Substantia nigra pars } \\
\text { reticulata }\end{array}$ & $\begin{array}{c}\text { a) } 1 \mathrm{~h} \\
\text { b) } 5 \mathrm{~h} \text { and } 24 \mathrm{~h}\end{array}$ & $\begin{array}{l}\text { a) ISI of } 60 \mathrm{sec} \text { revealed highest } \\
\text { antiepileptic efficacy } \\
\text { b) } 99 \% \text { of SWD disrupted by stimula- } \\
\text { tion, but increase in SWD number in } \\
5 \text { h session; } \\
72 \% \text { of SWD disrupted by stimulation } \\
\text { and decrease in SWD number in } 24 \mathrm{~h} \\
\text { session }\end{array}$ \\
\hline $\begin{array}{l}\text { Lüttjohann \& van } \\
\text { Luijtelaar, } 2013\end{array}$ & WAG/Rij & $\begin{array}{c}\text { Repeated (closed-loop), unilateral, } 130 \\
\text { Hz, } 1 \text { sec pulse train }\end{array}$ & $\begin{array}{l}\text { Ventral Posterior-Medial } \\
\text { thalamic nucleus, } \\
\text { Anterior thalamic } \\
\text { nucleus }\end{array}$ & $8 \mathrm{~h}$ & $\begin{array}{c}89 \% \text { of SWD disrupted by stimulation, } \\
\text { no increase or decrease in SWD } \\
\text { number }\end{array}$ \\
\hline Blik, 2015 & WAG/Rij & $\begin{array}{l}\text { Unilateral, closed (at threshold inten- } \\
\text { sity) } 1 \mathrm{sec} \text { monophasic pulse train; } \\
\text { open loop (continuous at } 50-70 \% \text { of } \\
\text { threshold intensity); both } 100 \mathrm{~Hz} \text {. }\end{array}$ & $\begin{array}{l}\text { Tuberomamillary nucle- } \\
\text { us }\end{array}$ & $3 \mathrm{~h}$ & $\begin{array}{l}\text { Closed-loop interrupted but elevated } \\
\text { number of SWD and fragmented bouts } \\
\text { of wakefulness. Open-loop stimulation } \\
\text { at } 70 \% \text { threshold reduced number of } \\
\text { SWD by } 40 \% \text { and raised active } \\
\text { wakefulness and decreased slow-wave } \\
\text { and REM sleep }\end{array}$ \\
\hline
\end{tabular}

(Table 1) Contd.... 


\begin{tabular}{|c|c|c|c|c|c|}
\hline Author (year) & $\begin{array}{l}\text { Model or type of } \\
\text { epilepsy }\end{array}$ & Type of stimulation & Stimulation site & $\begin{array}{l}\text { Frequency and dura- } \\
\quad \text { tion of session }\end{array}$ & Outcome \\
\hline $\begin{array}{l}\text { van Heukelum et } \\
\text { al., } 2016\end{array}$ & WAG/Rij & $\begin{array}{c}\text { Closed-loop, unilateral, } 130 \mathrm{~Hz} \text {, } \\
1 \mathrm{sec}\end{array}$ & Somatosensory cortex & $24 \mathrm{~h}$ & $\begin{array}{l}91 \% \text { of SWD disrupted by stimulation, } \\
\text { decrease in SWD number during } \\
\text { stimulation session and some hours of } \\
\text { the post-stimulation recording session }\end{array}$ \\
\hline $\begin{array}{l}\text { Maximenko et al., } \\
2017\end{array}$ & WAG/Rij & $\begin{array}{l}\text { Closed-loop, unilateral, } 130 \mathrm{~Hz} \\
\text { triggered by SWD precursors, } 1 \\
\text { sec }\end{array}$ & Somatosensory cortex & $1 \mathrm{~h}$ & $\begin{array}{l}72 \% \text { reduction of SWD time based on } \\
\text { combination of SWD prediction - } \\
\text { prevention and SWD detection - } \\
\text { disruption }\end{array}$ \\
\hline \multicolumn{6}{|c|}{ Optogenetic Stimulation } \\
\hline Kros et al., 2015 & $\begin{array}{c}\mathrm{C} 3 \mathrm{H}, \\
\text { Tottering mouse }\end{array}$ & $\begin{array}{l}\text { Closed-loop optogenetic } \\
\text { stimulation using ChR2 either } \\
\text { unilateral or bilateral }\end{array}$ & Cerebellar nuclei & Not reported & $\begin{array}{l}\text { Unilateral: } 91.8 \% \text { of disrupted SWD, } \\
\text { bilateral: } 93.4 \% \text { of disrupted SWD }\end{array}$ \\
\hline Sorokin et al., 2017 & WAG/Rij & $\begin{array}{l}\text { Closed-loop optogenetic } \\
\text { stimulation using stable step } \\
\text { function opsins }\end{array}$ & $\begin{array}{l}\text { Ventral Posterior- Medial } \\
\text { thalamic nucleus }\end{array}$ & $20-60 \mathrm{~min}$ & $\begin{array}{c}\text { Disruption of ongoing SWD, percent- } \\
\text { age / success rate not reported }\end{array}$ \\
\hline \multicolumn{6}{|c|}{ Noninvasive Stimulation } \\
\hline Berényi et al., 2012 & $\begin{array}{c}\text { Long-Evans rats with } \\
\text { generalized absence } \\
\text { epilepsy }\end{array}$ & $\begin{array}{c}\text { Closed-loop transcranial } \\
\text { electrical stimulation (TES), } \\
\text { Spike triggered stimulation by } \\
50 \text {-ms Gaussian waveform. } \\
\text { Delay between spike and } \\
\text { stimulus onset } 0,10 \text { or } 40 \mathrm{~ms} \text {. } \\
\text { Intensity: } \max 4-5 \mathrm{~V} \text {. }\end{array}$ & $\begin{array}{l}\text { Bilateral strip electrodes with } \\
\text { same polarity above barrel } \\
\text { cortex and one above anterior } \\
\text { midline with opposite polarity. } \\
\text { TES applied either between left } \\
\text { and right or between bitemporal } \\
\text { electrodes against frontal } \\
\text { midline (whatever worked best) }\end{array}$ & $\begin{array}{l}\text { Multiple (5-24) } 10 \mathrm{~min} \\
\text { sham and TES sessions } \\
\text { while the rat was sitting } \\
\text { still in his home cage }\end{array}$ & $\begin{array}{l}>60 \% \text { decrease time spent in SWD due } \\
\text { to shorter mean duration; No rebound } \\
\text { or long-term compensatory increase of } \\
\text { their probability of occurrence. Ampli- } \\
\text { tude of the spike was }\end{array}$ \\
\hline $\begin{array}{c}\text { Zobeiri \& van } \\
\text { Luijtelaar, } 2013\end{array}$ & WAG/Rij & $\begin{array}{l}\text { Open loop Transcranial anodal } \\
\text { and cathodal direct current } \\
\text { stimulation (tDCs), Exp I and } \\
\text { II: } 100 \mu \mathrm{A} \text {; Exp III: } 150 \mu \mathrm{A}\end{array}$ & $\begin{array}{l}\text { Two stimulation electrodes } \\
\text { (either anodes or cathodes) } \\
\text { bilaterally on skull above the } \\
\text { epileptic foci of the somatosen- } \\
\text { sory cortices, reference elec- } \\
\text { trode on frontal cortex }\end{array}$ & $\begin{array}{l}\text { Exp I: } 4 \text { series of } 15 \text { min } \\
\text { counterbalanced catho- } \\
\text { dal and anodal stimula- } \\
\text { tion interstimulation } \\
\text { interval (ISI) } 1 \mathrm{~h} 45 \\
\text { min; } \\
\text { Exp II and III: } 4 \text { series } \\
\text { of } 15 \text { min cathodal } \\
\text { stimulation, ISI } 1 \mathrm{~h} 45 \\
\text { min }\end{array}$ & $\begin{array}{l}\text { Exp I: Anodal stimulation tended to } \\
\text { increase, cathodal to decrease number } \\
\text { SWD. } \\
\text { Exp II \& III: reduction in number } \\
\text { SWD during stimulation and increase } \\
\text { (II) or decrease (III) in mean duration } \\
\text { of SWD during ISI }\end{array}$ \\
\hline $\begin{array}{l}\text { Zobeiri \& van } \\
\text { Luijtelaar, this } \\
\text { chapter }\end{array}$ & WAG/Rij & $\begin{array}{l}4 \text { series of } 15 \text { or } 30 \text { minutes of } \\
\text { cathodal transcranial } 1 \text { direct } \\
\text { current stimulation (ctDCs) }\end{array}$ & $\begin{array}{l}\text { On skull above left and right } \\
\text { focal zone in somatosensory } \\
\text { cortex, reference electrode on } \\
\text { animal's chest }\end{array}$ & $\begin{array}{l}\text { intensity } 150 \mu \mathrm{A}, \\
\text { ISI } 1 \mathrm{~h} 45 \mathrm{~min} \text { or } 1 \mathrm{~h} 30 \\
\text { min. }\end{array}$ & $\begin{array}{l}\text { Reduction in number and mean } \\
\text { duration of SWD on stimulation day } \\
\text { with both protocols. } \\
\text { 30-min protocol reduced number and } \\
\text { mean duration on post stimulation day. }\end{array}$ \\
\hline $\begin{array}{l}\text { Godlevsky et al., } \\
2006\end{array}$ & WAG/Rij & $\begin{array}{c}1 \text { series of } 3 \text { transcranial mag- } \\
\text { netic stimulation (TMS) }\end{array}$ & Motor cortex & $\begin{array}{l}1.5 \mathrm{sec}(2 \mathrm{~Hz}) \text {, at } \\
\text { threshold intensity }\end{array}$ & $\begin{array}{l}\text { Non-sign reduction in SWD time for } \\
\qquad 30 \text { min after TMS }\end{array}$ \\
\hline
\end{tabular}

When the anti-epileptic efficacy of automated responsive DBS (rDBS) of the substantia nigra reticulata was examined in freely moving GAERS for periods of up to 24 hours using an online SWD detection algorithm based on permutation entropy [129], 100\% of sensibility of the seizure detection algorithm was obtained [130]. Seizure detection was excellent for short-term recordings, (up to $99 \%$ ), whereas for long-term recordings (24- h) it dropped to $72 \%$, probably due to the increase in EEG components resembling SWDs (e.g. sleep spindles, feeding and grooming artifacts). At other periods SWDs occurred more frequently in clusters and were refractory. Despite these to-be-solved issues, the anti-epileptic efficacy of this way of stimulation was stable over therecording time [130]. Closed-loop high-frequency stimulation $(130 \mathrm{~Hz})$ of the thalamic Ventro-Posterior-Medial nucleus (VPM) in freely moving WAG/Rij rats also disrupted ongoing SWDs in about $89 \%$ of cases. By contrast, open loop low frequency stimulation (1 sec pulsetrains of $8 \mathrm{~Hz}$ ) induced SWD-like afterdischarges while the same stimulation in the anterior thalamic nucleus, i.e., outside of the SWD-relevant brain network, only rarely induced an afterdischarge. The rhythmic activation of the VPM by low frequency stimulation, might provide a 'trigger input' to the cortical focus, via the direct excitatory projections of the VPM to the SoCx [131]. In contrast, 
high frequency stimulation of the VPM might have a desynchronizing effect on the network, hampering sustainment of SWDs, in line with outcomes of previous studies in GAERS [132]. Closed-loop $100 \mathrm{~Hz}(1 \mathrm{sec}$ trains) stimulation of the tuberomamillary nucleusin the brain stem in WAG/Rij rats also aborted SWDs but elevated the number of SWDs and fragmented bouts of wakefulness in a $3 \mathrm{hr}$ recording session [133]. Open-loop stimulation at SWD interruption intensity of $70 \%$ reduced the number of SWDs by $40 \%$ and raised active wakefulness and decreased slow-wave and REM sleep [133].

\subsection{Cortical Stimulation}

The effects of $24 \mathrm{hrDBS}$ in the cortical focal zone on SWDs and behaviour were investigated in WAG/Rij rats [134]. The authors delivered short $(1 \mathrm{sec})$ DBS trains of $130 \mathrm{~Hz}$ in the deep layers of the SoCxusing a previously validated SWD detection algorithm while rats of the yoked control group were stimulated at the same time. In addition to a robust disruption of ongoing SWDs by the stimulus train, the authors observed a reduction in the number of SWDslasting severalhours after the end of the stimulation, see Fig 2. This suggests that DBS stimulation may induce local neuromodulatory effects such as long-term depression or long-term potentiation in the reciprocally connected thalamus (VPM), known to display an increased tonic inhibition in absence epileptic rats [135]. Interestingly, induction of these neuromodulatory effects critically depended on the timing of stimulation: in other words, reduction in the number of SWDs during the $24 \mathrm{hr}$ following stimulation was only seen in the group in which DBS was immediately applied upon SWD onset but not in the yoked control group [134].

Open loop stimulation at a single cortical site with a single pulse or 2 pulses separated $400 \mathrm{msec}$ or $8 \mathrm{~Hz}$ stimulation in the thalamus may elicit afterdischarges, not different from SWDs [31, 136].

\subsection{A brain-Computer Interface for SWD Prevention?}

Based on the above cited studies, the feasibility of SWD prevention seems now within reach. It is based on a closed-loop pre- cursor detection - stimulation brain computer interface'. The online detection of SWD precursors on the EEG would allow to stimulate a brain region and prevent the occurrence of SWDs, similarly as was done in the SWD abortion studies. Recently, it was shown that SWDs are preceded by the simultaneous occurrence of delta and theta activity in cortex and thalamus [7], while network analyses showed that communication between these two brain structures already changed preictally [21, 30, 131, 137]. This led the group of Hramov et al to develop an algorithm for the detection of SWD precursors and to implement it in a closed-loop braincomputer interface(BCI) system, applying cortical high frequency electrical stimulation as soon as a precursor was detected [138, 139].

The algorithm predicted correctly $88 \%$ of SWDs, albeit with a large number of false positives, mainly during light slow-wave sleep, see Fig. 3. Adaptation of the algorithm to reduce the number of false detections had a trade-off insensitivity. Although sensitivity and specificity of this on-line SWD prediction system remains to be improved, it opens a new line of research, searching for optimal 'responsive' precursor detection and stimulation protocols for seizure prevention. Most relevant is that the studiesdescribed so far provide a methodological approach for experiments with longer lasting sessions, making it necessary to validate the stability of DBS over several days. The current development of new programmable implantable devices should make it more feasible to assess chronic effects of DBS in epilepsy and in the genetic AE models. These models will be valuable preclinical tools to further develop and implement these protocols that could be then subsequently applied to other models, e.g in models of drug-resistant epilepsies.

\subsection{Optogenetic Stimulation}

Optogenetic, a very recent form of brain stimulation has been applied in different models of neurological diseases. Specific cell types and neuronal populations are transfected with light-sensitive opsins, which either inhibit or activate the transfected neurons upon light stimulation delivered to the brain structure via an optical fiber [140]. As for electrical stimulation, optogenetic stimulation can be

\section{closed-loop stimulation}

yoked stimulation
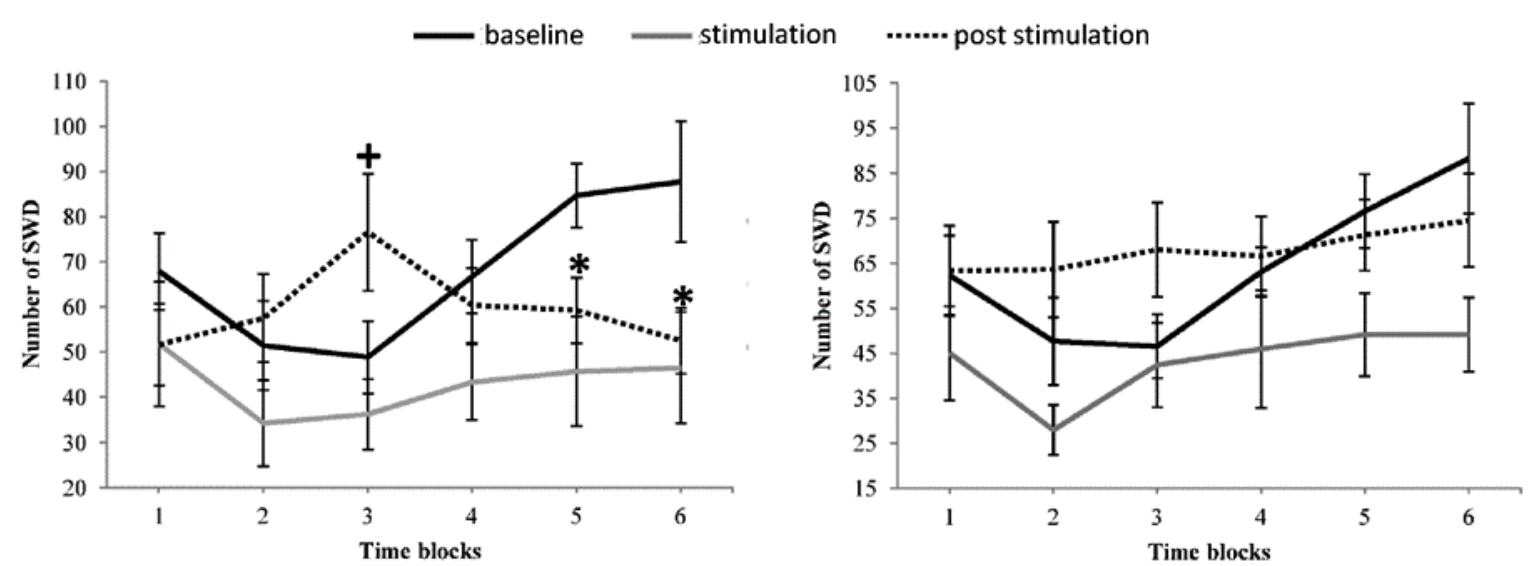

Fig. (2). Effect of timing of stimulation. WAG/Rij rats were stimulated in pairs: one animal received closed-loop stimulation (a $1 \mathrm{sec}$ pulse train of $130 \mathrm{~Hz}$, $0.4 \mathrm{sec}$ pulse duration) whenever a SWD was present in its EEG; the coupled partner received the same type of stimulation ( $1 \mathrm{sec}$ pulse train of $130 \mathrm{~Hz}$, $0.4 \mathrm{sec}$ pulse duration) at the same moment in time, independent of whether it showed a SWD or not (yoked stimulation). Comparison of SWD number is done between a 24 hours baseline session, the 24 hours stimulation session and a 24 hours post-stimulation session. Data are average SWD numbers of 7 rats per group. Note that each of the 24 hour sessions is divided into 6 time-blocks: time-block 1: $12^{30}-16^{30}$, time-block 2: $16^{30}-20^{30}$, time-block $3: 20^{30}-00^{30}$, timeblock 4: $00^{30}-04^{30}$, time-block 5: $04^{30}-8^{30}$, time-block 6: $8^{30}-12^{30}$. Next to an overall decrease in SWD number during the stimulation as compared to the baseline session seen for both groups, a significant decrease in SWD number (as compared to baseline) was found for the closed-loop group during the last two time-blocks of the post-stimulation session (indicated by an *). A + indicates a significant change in SWD number in this time-block compared to the same time block during the stimulation day (adapted after [134]). 

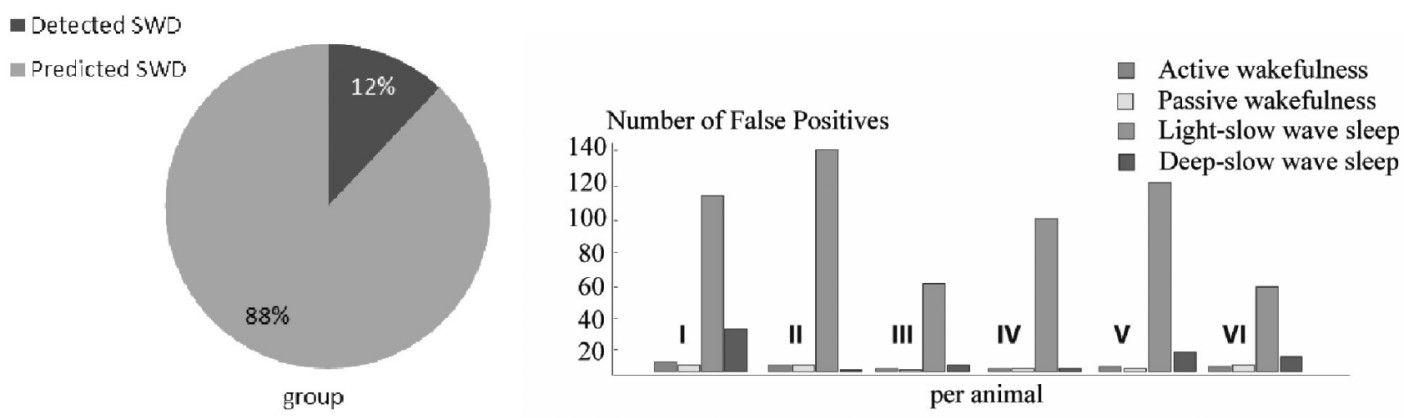

Fig. (3) Performance of SWD prediction algorithm. Percentage of predicted (88\%) and detected (12\%) SWDs within 4 hours recording of the six WAG/Rij rats (left panel). No SWD remained undetected; Number of false positives across different states of alertness (right panel). Note, for each rat and each state of alertness, 5 segments of 50 seconds duration were randomly selected in each recording for quantification of the false alarm rate (adapted after [139]).

either applied using intermittent ('open-loop') or responsive ('closed-loop') protocols. Optogeneticsis preferably used to disentangle the contribution of a particular element of a brain network in seizure generation and termination. Kros and colleagues (2015) demonstrated that 'optogenetic closed-loop' activation of neurons of the cerebellar nuclei successfully disrupt ongoing SWDs in two mouse models of absence epilepsy (the mutant tottering mouse and the $\mathrm{C} 3 \mathrm{H}-\mathrm{HeJ}$ mouse), while the same stimulation applied to the cerebellar cortex was inefficient. Since the cerebellar nuclei send excitatory projections to the thalamus, the authors argued that activation of the remote cerebellar nuclei has changed the balance of excitation and inhibition in the thalamic relay nuclei and alsothe bursting firing mode to the tonic one, therefore SWDs were aborted [141]. This balance is usually created by an interplay between the direct cortical projectionsproviding excitation to thalamic relay and RTN cells and inhibition provided by the RTN to relay cells [141, 142]. Sorokin et al. transfected thalamo-cortical neurons of the VPM with stable step function opsins. With this technique, they were able to switch phasic bursting of these neurons, as observed during SWDs, into a tonic firing pattern upon light stimulation. Implemented in a closed-loop BCI, this stimulation disrupted ongoing SWDs in freely moving WAG/Rij rats [142]. Interestingly, triggering burst firingin these relay neurons by optogenetic stimulation was sufficient to generate SWDs in these epileptic rats, suggesting that excitatory cortical input to the thalamus might contribute to the occurrence of SWDs.

\subsection{Non-invasive Stimulation}

Closed-loop stimulation systems have also been applied in less invasive stimulation settings. Berenyi et al., [144] provided closedloop transcranial $50 \mathrm{msec}$ Gaussian waveforms to Long-Evans rats with SWDs via bilateral plate electrodes with 5 contact points in the anterior-posterior axis placed on the skull above the barrel cortex or between the barrel and frontal cortex, whatever worked the best. Stimulation was triggered by a real-time spike detection method; it shortened SWDs by quenching the ongoing rhythm through widespread cortical stimulation [143]. The use of these particular plate electrodes over the left and rignt barrel cortexdiffuses the applied currents over a large cortical area. This mightexplain why in this case single pulses interrupted SWDs.

Transcranial direct current stimulation (tDCS) is a noninvasive brain stimulation technique with potential clinical benefits fora range of neurological disorders including Parkinson's disease, major depression, Alzheimer's disease and also some types of focal epilepsies with a cortical origin [144-146]. A clinical trial reported that a single 20 -min session of tDCS $(1 \mathrm{~mA})$ over the epileptogenic focus of patients with cortical dysplasia reduced the discharge frequency, with a trend towards a decrease in the number of clinical seizures [147]. A weak constant electrical current, applied through scalp electrodes, can modulate the underlying cortical neural activ- ity by either affecting the neuronal firing rate and pattern or changing the synaptic release probability [148]. The two forms of tDCS, anodal (atDCS) and cathodal tDCS (ctDCS) refer respectively to the application of positive and negative current to the target area. In general, atDCS results in an overall increase in cortical excitability, whereas ctDCS induces cortical inhibition. The latter is of particular relevance in the treatment of focal types of epilepsy asthese types of epilepsy are often considered to result from too much excitation and/or too little inhibition [149,150].Using bilateral tDCS stimulation over the SoCx in WAG/Rij with a third electrode on frontal cortex serving as a reference (Fig4.A), allowing current flow over a large part of the cortex, Zobeiri and van Luijtelaar (2013) [151] showed that only ctDCSreduced the number of SWDs (Fig. 4C) and tended to decrease the mean duration. The antiepileptic effect of ctDCS was intensity-dependent from 100 to $150 \mu \mathrm{A}$. Spectral analyses of the EEG during the 15 -min stimulation at $150 \mu \mathrm{A}$ stimulation showed an increase in power of delta (1-4 Hz) and subdelta $(0.5-1 \mathrm{~Hz})$ bands, suggesting that ctDCS hyperpolarized the cell membranes in the stimulated area. $150 \mu \mathrm{A}$ ctDCS had also, albeit short, lasting after effects on mean duration of SWDs over the 1-hour 45-minute inter-stimulation interval.

The efficacy of tDCS can be increased by reducing the electrode size or using an extracephalic reference electrode [152] and this might have consequences for the duration of the desired effects. We tried to increase the focality of ctDCS above the focal cortical zone in WAG/Rij rats by replacing the frontal electrode by a reference chest electrode (Fig.4B). In this case,30-min stimulation yielded a larger effect than 15-min and the antiepileptic effects of 30 -min outlasted the stimulation period (Fig.4D). Number and mean duration of SWDs tended to be lower than baseline values on the day following stimulation suggesting long-term effects. However, these long-term effects were not seen when stimulationwas restricted to $4 \times 15 \mathrm{~min}$.

Antiepileptic effects of ctDCS and not atDCS were reported in other animal models for different types of epilepsy, such as cortical ramp-stimulation, a model for acute focal seizures [153] and PTZinduced generalized tonic-clonic seizures in rats [154], as well as in the pilocarpine status epilepticus model [155], where neuroprotective effects for ctDCS were found. It has been proposed that if the second stimulation session takes place during the aftereffects of the first session, the antiepileptic effect of ctDCS is prolonged [156]. Intensity and duration of stimulation, as well as position and size ofactive and reference electrodesare important parameters which define the efficacy of tDCS $[152,157]$. Finally, the effects of repetitive stimulations need to be investigated in AEmodels, as was done in patients with mesial temporal lope epilepsy [146]. It is important to emphasize that there are also safety restrictions to DC stimulation and therefore strategies to prolong or increase the intensity of the stimulationarelimited. 


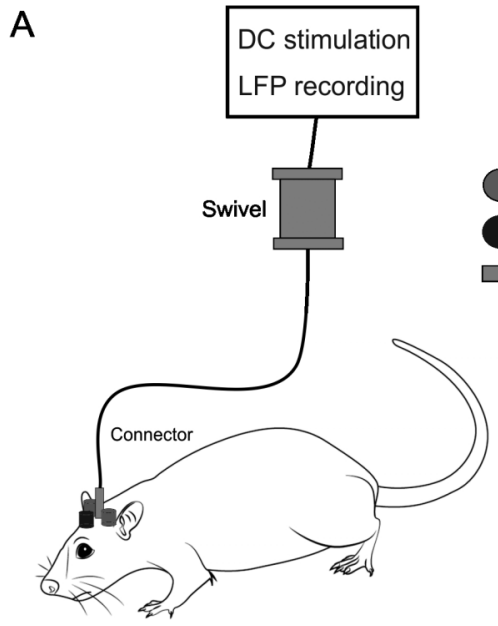

C

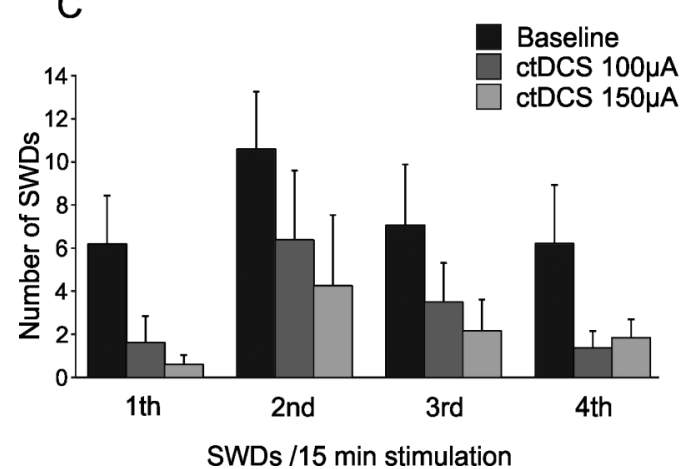

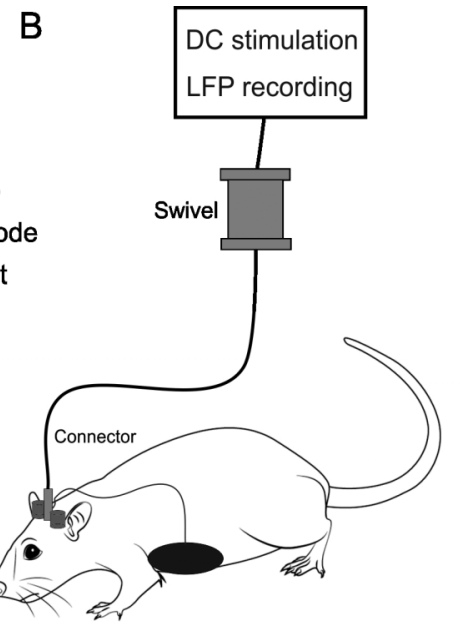

$\mathrm{D}$
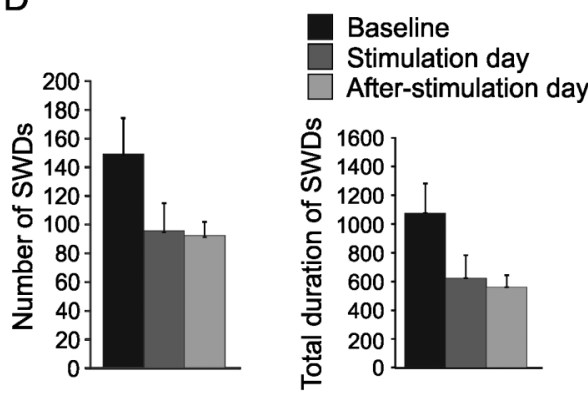

SWDs / $8 \mathrm{~h}$

Fig. (4). Effects of transcranial direct current stimulation (tDCS) on absence epilepsy. A Simplified scheme of tDCS montage on the rat skull, indicating the location of two active bilateral electrodes (in light grey) on the excitable zones of the somatosensory cortices and a reference electrode on the frontal cortex. B. Simplified scheme of tDCS montage on the rat skull, indicating the location of two bilateral active electrodes (in light grey) on the excitable zones and the reference electrode (in black) on the chest. This montage was used to increase the focality of the stimulation on the epileptogenic zones of the somatosensory cortices. C. Bar graph indicating theintensity-dependent antiepileptic effects of repeated cathodal tDCS (ctDCS) on number of spike-wave discharges (SWDs) in WAG/Rij rats using the tDCS electrode montage shown in A. Each rat received 4 series of 15 -minute cathodal stimulation with the intensity of either 100 or $150 \mu \mathrm{A}$ and interstimulation interval of one hour 45 minutes while LFP was recorded and behavior was monitored. D. Left panel illustrating the effects of 4 times 30 min repeated ctDCS $150 \mu \mathrm{A}$ spread over an eight-hour period on number of SWDs, using the tDCS electrode montage shown in B. Note the significant long-lasting reduction in the number of SWDs one day after ctDCS as was established in a $8 \mathrm{hr}$ recording session. D. right panel indicates the significant reduction in the total duration of SWDs both at stimulation day and the day after stimulation cessation.

The results of these studies propose that ctDCS canbe used as a possible therapeutic non-invasive brain stimulation method in epilepsy, including AE. However, evidence that the effects of ctDCS outlast the duration of the stimulation period in epilepsy patients or in experimental epilepsy animal studies is scarce. Although the short lasting effects of ctDCS seem to be directly dependent on the polarization of the neuronal cell membrane, the after effects appear mostly associated with more complexcellular and network mechanisms including "gene activation/regulation, de novo protein expression, morphological changes, changes in intrinsic firing properties and modified network properties resulting from changed inhibition, homeostatic processes and glial function and genetic variations in neuronal network functioning" [158, 159]. Early pharmacological studies suggest that after effects of ctDCS may result from persistent modification of synaptic efficacy similar to those underlying long-term depression as well as a reduction in glutamate and GABA [160-162]. Future tDCS research should focus on optimization of stimulation parameters and factors such asstimulation intensity, duration, repetition rate, repetition interval and electrode montage including the location of the reference, as well as safety issues.

A single study described the effects of transcranial magnetic stimulation (TMS) in the genetic models [163]. TMS $(0.5 \mathrm{~Hz}, 3$ impulses) was applied in WAG/Rij rats at threshold intensity to the motor cortex and its effects on SWDs were compared with a sham stimulation group. TMS reduced the number of SWDs by $31.4 \%$ in comparison with the sham group in the first $30 \mathrm{~min}$ from the moment of cessation of stimulation. The number of SWDs returned to pre-stimulation level after $90-150$ minutes. It is obvious that also TMS could be an intervention option, however, more experiments need to be done before this can be considered for clinical trials.

\section{RADIOSURGERY USING SYNCHROTRON- GENERATED MICROBEAMS}

Traditional bilateral resective surgery of the SoCx in acutely prepared WAG/Rij rats was shown to reduce all SWDs [164]. However, this drastic option will not be easily translated, perhaps only in children with a frontal type of absence epilepsy with large cognitive detoriations. Radiosurgery may represents a promising therapeutical alternative and modern radiosurgical devices such as Gamma Knife ${ }^{\circledR}$ and Cyberknife ${ }^{\circledR}[165]$ have already yielded encouraging results in different types of epilepsies [166]. However, the radiosensitivity of the healthy tissue arround the epileptic foci is the limitation factor in this type of treatment [167]. In contrast, 'lowenergy photons generated by $3^{\text {rd }}$ generation synchrotron sources allows the deposition of extremely steep lateral dose fall-off and provides sufficient precision to perform experimental studies in animal models of epilepsy' [168]. Recently, researchers at the Euro- 
European Synchrotron Radiation Facility (ESRF) in Grenoble used spatial fractionation of ionizing radiation in the microscopic range. It allowed to produce 'sharply defined beam edges deep in the tissues with a high dose rate and to investigate the effects of arrays of 25-75 $\mu \mathrm{m}$-wide beam slices spaced $50-200 \mu \mathrm{m}$ on centre' [169]. Surprisingly, using this protocol, animals tolerate doses of hundreds, or even thousands of gray of such microbeams delivered to their brains [169], with tissue damage confined to the microbeams tracks [170].

'By rotating the brain around a center of rotation using a goniometer, it is possible to precisely "interlace" microbeams to deposit a high homogeneous radiation dose into discrete brain regions, with no extension on neighboring tissue [171]. The possibility of accurate targetting of the epileptic zone, as well as preservation of surrounding tissues, makes this procedure clinically attractive for many types of pathologies which require destruction, inactivation and/or disconnection of small brain regions, even close to eloquent or vital structures. The efficacy of this technique was first testedin rodent brain tumor treatment and later on it was also used for other brain diseases such as epilepsies.

The GAERS model with its well described ictogenic neurons in the SoCx was used for a proof of principle [38], also because there is no gross cell loss and/or sclerosis in this model therefore avoiding confounding factors in therapy evaluation. Of note, it is obvious that such therapy will never beapplied to AE patients or only in cases of serious deteriorating types of epilepsy. The group of Antoine Depaulis targeted brain regions using spatially fractionated beams into an array of parallel microbeams [38] to achieve microtransections aimed at "disconnecting" tissue slices from each other, and to avoid spreading of epileptic activity over the cortex. The correct targeting of the SoCx was verified in each animal by $\mathrm{T}_{1^{-}}$ weighed MRI within the two weeks that followed irradiation, confirming the precision of radiation targeting and insignificant alterations in the surrounding tissues. Histopathological verification of the radiated tissue revealed minor structural tissue damage in a period of 2 monthsafterirradiation. The microbeam tracks were clearly visible in the SoCxon histological brain sections, as thin clear stripes alternating with darker, non-irradiated tissue. Radiation effects were also confirmed on immuno-labeled slices with different neuronal markers, astrocytes, basal lamina, angiogenesis and glucose transporter. Although the SoCx was targeted bilaterally, no significant behavioral alterations were measured with Rotarod ${ }^{\circledR}$ and open-field tests 2 weeks post-irradiation. These control studies confirmed that this type of synchrotron-generated microbeams have limited deleterious effects on brain tissue and motor or cognitive behaviors [38].

During the 4 months that followed irradiation, EEG recordings showed that microbeam irradiation suppressed SWDs when the whole SoCx was irradiated. 'While non-irradiated cortical and thalamic regions could still produce epileptic discharges, the irradiated volume became isolated from the pathological activity. In contrast, irradiation of the motor cortex or ventrobasal thalamus did not significantly suppress SWDs' [38]. The mechanisms of the functional exclusion of the SoCxwas further investigated by individually recording irradiated neurons two months after irradiation using in vivo intracellular electrophysiological recordings, as described before [19]. 'This approach revealed that the irradiated pyramidal neurons were strongly hyperpolarized, displayed a decreased excitability and a reduction of spontaneous synaptic activities' [38]. 'These functional alterations may explain the suppression of paroxysmal oscillations within irradiated cortical networks. This work provided the first post-irradiation electrophysiological recordings of individual neurons. As such, these recordings are a preliminary and critical step towards understanding how ionizing radiation energy delivery impacts neuronal physiology and pathophysiology. Indeed, our data should provide clues on how radiation dose should be delivered for targeting epileptic neuronal networks'. This approach also allows to decipher the role of horizontal connection with the SoCx in the synchronization of neurons involved during SWDs.

\section{NEUROFEEDBACK}

Neurofeedback training is a non-invasive therapeutical approach and positive effects were reported in drug-refractory patients including some with AE. Extended training involved feedback and instrumental conditioning aiming to reduce the slow cortical potentials (SCP), an assumed marker of excitability. Most relevant is that some of thepatients with epilepsy were able to achieve a reduction in seizure occurrence [172]. The sample size and the heterogeneity of the studied population hampered clear conclusions. Indeed, not all patients could learn to reduce their SCP and there were few follow-up studies. Based on the neuro-feedback studies on cats, it is more suitable to enhance the sensory motor rhythms (SMR, 12$15 \mathrm{~Hz}$ ) at central locations, sincethese regions areneurophysiologically associated with alert and motionless processes [173]. SMR production appears to reduce in patients with epilepsy, while theta (4-9 Hz) oscillations are increasedwhen compared withnormal subjects $[173,174]$. However, methodological issues (heterogeneity of patient population, small number of subjects, proper pre-training EEG controls, proper control groups, motivation of the subjects, placebo effects) hamper clear conclusions about the effectiveness of neuro-feedback training. Animal studies using genetic models of $\mathrm{AE}$, might indicate whether SWDs are under operant control, a precondition for effective neuro-feedback training. Osterhagen et al. reinforced SWDs by the presentation of a sucrose pellet during 10 sessions in WAG/Rij rats [175]. A BCI system controlled the training phase of the experiment, during which the occurrence of SWDs was immediately followed by the presentation of reward. Reinforcing SWDs decreased SWDs occurrence during training, the opposite of what was trained and aimed at. Moreover, it was also found that this decrease in SWDs during the training phase were not persistent in the post-training sessions. Because behavioural states are knownto heavily modulate the occurrence of SWDs (SWDs do not occur during arousal but preferentially occur during passive wakefulness, drowsiness and light slow wave sleep), it was proposed that increased arousal, experimentally created by the availability and presentation of the palatable foot pallets consequently resulted in fewer SWDs. Additional control tests supported this hypothesis and therefore precluded a clear answer whether SWDs can really become under operant control, the latter is a sine qua non condition for successful neurofeedback training. Interestingly, the fact that SWDs are preceded by precursor activity might offer the possibility to use neurofeedback training to prevent the occurrence of this precursor activity, an option to control SWDs.

\section{CONCLUDING REMARKS}

Despite the introduction of LTG, ZNS and LEV, treatment of $\mathrm{AE}$ has not been much renewed for the last 50 years. The first generation AEDs, ETX and VPA are still the drugs of choice. Interestingly, which of the two drugs might work the best appears now predictable. We propose that the main reason for the high efficacy of ETX has been elucidated in the genetic models: it blocks the excitable cells in the initiating cortical regions and additional seizure control isachieved by its action on thalamic cells, its action on $\mathrm{Na}^{+}$currents and on cortical GABA. Another important contribution for the success of ETX is that it may have antiepileptogenic effects in children with absence epilepsy and in the genetic models, although this is still debated. The acute reduction of absence seizures by ETX may contribute to the long term outcomes after chronic treatment (antiepileptogenesis) and we propose that the combined actions of ETX can be summarized as that "seizure suppression begets seizure remission". The reason why VPA is also rather effective as an anti absence agent is less clear; its mode of action is plural. It is primarily a voltage-dependent $\mathrm{Na}^{+}$channel blocker. Blockage of these channels in the SoCx with phenytoin reduces SWDs [63]; whereas blocking $\mathrm{Na}^{+}$channels in the thalamus 
enhances SWDs, as was demonstrated with CBZ [176]. Therefore, blocking voltage dependent $\mathrm{Na}^{+}$channels alone cannot explain the efficacy of VPA. Interestingly, the action of CBZ in the thalamus was antagonized by the GABAa antagonist bicuculline, suggesting that the SWD enhancing effects of CBZ could be ascribed to GABA mimetic effects in the thalamus. Indeed, increased thalamic GABA-ergic inhibition is a key factor in the genetic models [135, 177]. Other mechanisms, such as blockade of T-type $\mathrm{Ca}^{2+}$ channels, must be responsible for the favourable action of VPA in absence epilepsy. Local injection studies might be helpful to elucidate where VPA is acting. For clinical practice it is important that the antiepileptogenic effects of the $\mathrm{Na}^{+}$channel blockers, as found with CBZ, are absent in the genetic models [56] and that antiepileptogenesis effects in children with AE are much weaker upon VPA treatment when compared to ETX one [5]. The lower efficacy of LTG, another $\mathrm{Na}^{+}$channel blocker, was predicted by van Rijn et al., [178]: these authors found a small reduction in SWDs after the highest dose only. The working mechanism of LTG precludes it from a good efficacy considering supposed opposite actions on SWDs in cortex and thalamus, as can be assumed based on the action of other $\mathrm{Na}^{+}$channel blockers such as $\mathrm{CBZ}$ and phenytoin.

In the last 40 years, new therapeutical approaches have mainly targeted drug-resistant epilepsies with focal origins, not AE patients. However, several approaches can be considered in the future that could help patients with $\mathrm{AE}$, in particular when seizures persist during adulthood and/or when they are less benign.

Although AE is classified as a generalized form of epilepsy, recent data in animal models and AE patients suggest thatit shares with focal epilepsies the existence of a specific brain region that generate seizures, although the initiation zone is bilateral in AE. This implies that innovative therapeutical approaches can be designed to target and reduce the excitability of cells in the seizure generating zone. Targeting cortico-thalamo-cortical and/or thalamothalamic network activity with more specific drugs remains an efficient option. In particular, recent rodent studies suggest that chronic drug treatment could modify or delay AE epileptogenesis. In this respect, AE constitutes aprototypic form of idiopathic/generalized epilepsy that could help design innovative curative treatment during brain development. Indeed, although many of the experimental methods will never be used in AE patients, except in extremely difficult to treat cases, the experiments reported here might be helpful in designing experiments and procedures for less benign forms of epilepsy.

\section{CONSENT FOR PUBLICATION}

Not applicable.

\section{CONFLICT OF INTEREST} wise.

The authors declare no conflict of interest, financial or other-

\section{ACKNOWLEDGEMENTS}

The Nijmegen group acknowledges the indispensablecontributions of Clementina van Rijn, Elly-Willems van Bree, Gerard van Oijen, Hans Krijnen, SaskiaMenting-Hermeling, Vladimir Maksimenko, Vladimir Makarov (both Satatov Technical University, Russia), Sabrina van Heukelum, Valerio D'Amore, Richard Ngomba and other collaborators from Neuromed, Pozzili, It.The research leading to these results has received fundings allocated to AD from Inserm, Agence Nationale de la Recherche (ANR grants "Basalepi", "GliEpi" and "Epirad"), Fondation Française pour la Recherche sur l'Epilepsie (FFRE), Fédération de Recherche sur le Cerveau (FRC).We are greatful to our colleagues in Grenoble and Paris, Benoit Pouyatos, Florian Studer, Colin Deransart, Isabelle Guillemain, Guillaume Jarre, Raphel Serduc, François Estève, Séverine Mahon, Pierre-Olivier Polack, Olivier David and Stéphane
Charpier for their great contribution to the works reported in the present article.

\section{REFERENCES}

[1] Panayiotopoulos, C. P. Typical absence seizures and their treatment. Arch. Dis. Child.81, 351-5 (1999).

[2] Tenney, J. R. \& Jain, S. V. Absence Epilepsy: Older vs Newer AEDs. Curr. Treat. Options Neurol.16, 290 (2014).

[3] Glauser, T. A. et al. Ethosuximide, valproic acid, and lamotrigine in childhood absence epilepsy: initial monotherapy outcomes at 12 months. Epilepsia54, 141-55 (2013).

[4] Caplan, R. et al. Childhood absence epilepsy: Behavioral, cognitive, and linguistic comorbidities. Epilepsia49, 1838-1846 (2008).

[5] Berg, A. T., Levy, S. R., Testa, F. M. \& Blumenfeld, H. Long-term seizure remission in childhood absence epilepsy: Might initial treatment matter? Epilepsia55, 551-557 (2014).

[6] Jarre, G., Guillemain, I., Deransart, C. \& Depaulis, A. Genetic models of seizure and epilepsy in rats and mice. in Models of seizure and epilepsy (eds. Pitkänen, A., Buckmaster, P., Galanopoulou, A. \& Moshe, S.) (2016).

[7] Van Luijtelaar, G., Hramov, A., Sitnikova, E. \& Koronovskii, A. Spike-wave discharges in WAG/Rij rats are preceded by delta and theta precursor activity in cortex and thalamus. Clin. Neurophysiol.122, 687-695 (2011).

[8] van Luijtelaar, E. L. \& Coenen, A. M. Two types of electrocortical paroxysms in an inbred strain of rats. Neurosci. Lett.70, 393-7 (1986).

[9] Sarkisova, K. \& van Luijtelaar, G. The WAG/Rij strain: a genetic animal model of absence epilepsy with comorbidity of depression [corrected]. Prog. Neuropsychopharmacol. Biol. Psychiatry35, 854-76 (2011).

[10] Vergnes, M. et al. Spontaneous paroxysmal electroclinical patterns in rat: a model of generalized non-convulsive epilepsy. Neurosci. Lett.33, 97-101 (1982).

[11] Depaulis, A., David, O. \& Charpier, S. The genetic absence epilepsy rat from Strasbourg as a model to decipher the neuronal and network mechanisms of generalized idiopathic epilepsies. $J$. Neurosci. Methods260, 159-174 (2016).

[12] Vergnes, M., Marescaux, C., Depaulis, A., Micheletti, G. \& Warter, J. M. Ontogeny of spontaneous petit mal-like seizures in Wistar rats. Brain Res.395, 85-7 (1986).

[13] Jarre, G. et al. Building up absence seizures: Network and cellular processes of absence epileptogenesis in the genetic absence epilepsy rat from Strasbourg. Cereb. Cortex. 27, 4607-4623 (2017).

[14] Schridde, U. \& van Luijtelaar, G. The influence of strain and housing on two types of spike-wave discharges in rats. Genes. Brain. Behav.3, 1-7 (2004).

[15] Akman, O., Demiralp, T., Ates, N. \& Onat, F. Y. Electroencephalographic differences between WAG/Rij and GAERS rat models of absence epilepsy. Epilepsy Res.89, 185-193 (2010).

[16] Noebels, J. L., Qiao, X., Bronson, R. T., Spencer, C. \& Davisson, M. T. Stargazer: a new neurological mutant on chromosome 15 in the mouse with prolonged cortical seizures. Epilepsy Res.7, 129-35 (1990).

[17] Marescaux, C., Vergnes, M. \& Depaulis, A. Genetic absence epilepsy in rats from Strasbourg--a review. J. Neural Transm. Suppl.35, 37-69 (1992).

[18] Slaght, S. J. et al. On the activity of the corticostriatal networks during spike-and-wave discharges in a genetic model of absence epilepsy. J. Neurosci.24, 6816-25 (2004).

[19] Polack, P.-O. et al. Deep layer somatosensory cortical neurons initiate spike-and-wave discharges in a genetic model of absence seizures. J. Neurosci.27, 6590-9 (2007).

[20] Bosnyakova, D. et al. Some peculiarities of time-frequency dynamics of spike-wave discharges in humans and rats. Clin. Neurophysiol.118, 1736-1743 (2007).

[21] Lüttjohann, A. \& van Luijtelaar, G. The dynamics of corticothalamo-cortical interactions at the transition from pre-ictal to ictal LFPs in absence epilepsy. Neurobiol. Dis.47, 49-60 (2012).

[22] Meeren, H. K. M., Pijn, J. P. M., Van Luijtelaar, E. L. J. M., Coenen, A. M. L. \& Lopes da Silva, F. H. Cortical focus drives widespread corticothalamic networks during spontaneous absence seizures in rats. J. Neurosci.22, 1480-95 (2002). 
[23] Meeren, H., van Luijtelaar, G., Lopes da Silva, F. \& Coenen, A. Evolving concepts on the pathophysiology of absence seizures: the cortical focus theory. Arch. Neurol.62, 371-6 (2005).

[24] Sitnikova, E. \& van Luijtelaar, G. Cortical control of generalized absence seizures: effect of lidocaine applied to the somatosensory cortex in WAG/Rij rats. Brain Res.1012, 127-37 (2004).

[25] Klein, J. P. et al. Dysregulation of sodium channel expression in cortical neurons in a rodent model of absence epilepsy. Brain Res.1000, 102-9 (2004).

[26] Tenney, J. R., Duong, T. Q., King, J. A. \& Ferris, C. F. FMRI of brain activation in a genetic rat model of absence seizures. Epilepsia45, 576-82 (2004).

[27] Karpova, A. V, Bikbaev, A. F., Coenen, A. M. L. \& van Luijtelaar, G. Morphometric Golgi study of cortical locations in WAG/Rij rats: the cortical focus theory. Neurosci. Res.51, 119-28 (2005).

[28] van de Bovenkamp-Janssen, M. C., van der Kloet, J. C., van Luijtelaar, G. \& Roubos, E. W. NMDA-NR1 and AMPA-GluR4 receptor subunit immunoreactivities in the absence epileptic WAG/Rij rat. Epilepsy Res.69, 119-28 (2006).

[29] Onat, F. Y., Aker, R. G., Gurbanova, A. A., Ateş, N. \& van Luijtelaar, G. The effect of generalized absence seizures on the progression of kindling in the rat. Epilepsia48 Suppl 5, 150-6 (2007).

[30] Sitnikova, E. \& van Luijtelaar, G. Electroencephalographic precursors of spike-wave discharges in a genetic rat model of absence epilepsy: Power spectrum and coherence EEG analyses. Epilepsy Res. 84, 159-171 (2009).

[31] Lüttjohann, A., Zhang, S., de Peijper, R. \& van Luijtelaar, G. Electrical stimulation of the epileptic focus in absence epileptic WAG/Rij rats: assessment of local and network excitability. Neuroscience 188, 125-34 (2011).

[32] van Luijtelaar, G. et al. Anti-epileptogenesis: Electrophysiology, diffusion tensor imaging and behavior in a genetic absence model. Neurobiol. Dis.60, 126-38 (2013).

[33] Abbasova, K. R., Chepurnov, S. A., Chepurnova, N. E. \& van Luijtelaar, G. The role of perioral afferentation in the occurrenceof spike-wave discharges in the WAG/Rij modelof absence epilepsy. Brain Res.1366, 257-262 (2010).

[34] David, O. et al. Identifying Neural Drivers with Functional MRI: An Electrophysiological Validation. PLoS Biol.6, e315 (2008).

[35] Polack, P.-O., Mahon, S., Chavez, M. \& Charpier, S. Inactivation of the somatosensory cortex prevents paroxysmal oscillations in cortical and related thalamic neurons in a genetic model of absence epilepsy. Cereb. Cortex19, 2078-91 (2009).

[36] Polack, P.-O. \& Charpier, S. Ethosuximide converts ictogenic neurons initiating absence seizures into normal neurons in a genetic model. Epilepsia50, 1816-20 (2009).

[37] Chipaux, M., Charpier, S. \& Polack, P.-O. Chloride-mediated inhibition of the ictogenic neurones initiating geneticallydetermined absence seizures. Neuroscience192, 642-651 (2011).

[38] Pouyatos, B. et al. Synchrotron X-ray interlaced microbeams suppress paroxysmal oscillations in neuronal networks initiating generalized epilepsy. Neurobiol. Dis.51, 152-60 (2013).

[39] Chen, S., Wang, J. \& Siegelbaum, S. A. Properties of Hyperpolarization-Activated Pacemaker Current Defined by Coassembly of HCN1 and HCN2 Subunits and Basal Modulation by Cyclic Nucleotide. 117, (2001).

[40] Chen, S. Der, Yeh, K. H., Huang, Y. H. \& Shaw, F. Z. Effect of intracranial administration of ethosuximide in rats with spontaneous or pentylenetetrazol-induced spike-wave discharges. Epilepsia52, 1311-1318 (2011).

[41] Ding, L. \& Gallagher, M. J. Dynamics of sensorimotor cortex activation during absence and myoclonic seizures in a mouse model of juvenile myoclonic epilepsy. Epilepsia57, 1568-1580 (2016).

[42] Holmes, M. D., Brown, M. \& Tucker, D. M. Are \&quot;generalized\&quot; seizures truly generalized? Evidence of localized mesial frontal and frontopolar discharges in absence. Epilepsia45, 1568-79 (2004).

[43] Westmijse, I., Ossenblok, P., Gunning, B. \& van Luijtelaar, G. Onset and propagation of spike and slow wave discharges in human absence epilepsy: A MEG study. Epilepsia50, 2538-48 (2009).

[44] Kole, M. H. P., Bräuer, A. U. \& Stuart, G. J. Inherited cortical HCN1 channel loss amplifies dendritic calcium electrogenesis and burst firing in a rat absence epilepsy model. J. Physiol.578, 507525 (2007).
[45] Coppola, G. et al. Lamotrigine as first-line drug in childhood absence epilepsy: a clinical and neurophysiological study. Brain Dev.26, 26-9 (2004)

[46] Wilfong, A. \& Schultz, R. Zonisamide for absence seizures. Epilepsy Res.64, 31-34 (2005).

[47] Fattore, C. et al. A multicenter, randomized, placebo-controlled trial of levetiracetam in children and adolescents with newly diagnosed absence epilepsy. Epilepsia52, 802-9 (2011).

[48] Tenney, J. R. \& Glauser, T. A. The current state of absence epilepsy: can we have your attention? Epilepsy Curr.13, 135-40 (2013).

[49] Brigo, F. \& Igwe, S. Ethosuximide, sodium valproate or lamotrigine for absence seizures in children and adolescents ( Review ). Cochrane Database Syst. Rev. CD003032 (2017). doi:10.1002/14651858.CD003032.pub3.www.cochranelibrary.com

[50] Cnaan, A. et al.Second monotherapy in childhood absence epilepsy. Neurology88, 182-190 (2017)

[51] Shinnar, S. et al. Long-term outcomes of generalized tonic-clonic seizures in a childhood absence epilepsy trial. Neurology85, 110814 (2015).

[52] Franzoni, E. et al. Refractory absence seizures: An Italian multicenter retrospective study. Eur. J. Paediatr. Neurol.19, 660664 (2015).

[53] Benjamin, O. et al. EEG frequency during spike-wave discharges may predict treatment outcome in patients with idiopathic generalized epilepsies. Epilepsia52, 45-48 (2011).

[54] Glauser, T. A. et al. Pharmacogenetics of antiepileptic drug efficacy in childhood absence epilepsy. Ann. Neurol.81, 444-453 (2017).

[55] Bazyan, a S. \& van Luijtelaar, G. Neurochemical and behavioral features in genetic absence epilepsy and in acutely induced absence seizures. ISRN Neurol.2013, 875834 (2013).

[56] Russo, E. et al. Upholding WAG/Rij rats as a model of absence epileptogenesis: Hidden mechanisms and a new theory on seizure development. Neurosci. Biobehav. Rev.71, 388-408 (2016).

[57] Svob Strac, D. et al. Monoaminergic Mechanisms in Epilepsy May Offer Innovative Therapeutic Opportunity for Monoaminergic Multi-Target Drugs. Front. Neurosci.10, 492 (2016).

[58] Rimoli, M. G. et al. T-type channel blocking properties and antiabsence activity of two imidazo[1,2-b]pyridazine derivatives structurally related to indomethacin. Neuropharmacology56, 63746 (2009).

[59] Kovács, Z., Czurkó, A., Kékesi, K. A. \& Juhász, G. Intracerebroventricularly administered lipopolysaccharide enhances spike-wave discharges in freely moving WAG/Rij rats. Brain Res. Bull.85, 410-6 (2011).

[60] Citraro, R., Leo, A., Marra, R., De Sarro, G. \& Russo, E. Antiepileptogenic effects of the selective COX-2 inhibitor etoricoxib, on the development of spontaneous absence seizures in WAG/Rij rats. Brain Res. Bull.113, 1-7 (2015).

[61] Russo, E. et al. mTOR inhibition modulates epileptogenesis, seizures and depressive behavior in a genetic rat model of absence epilepsy. Neuropharmacology69, 25-36 (2013).

[62] Gandolfo, G. et al. $\mathrm{K}+$ channel openers decrease seizures in genetically epileptic rats. Eur. J. Pharmacol.167, 181-3 (1989).

[63] Gurbanova, A. A. et al. Effect of systemic and intracortical administration of phenytoin in two genetic models of absence epilepsy. Br. J. Pharmacol.148, 1076-82 (2006).

[64] Poolos, N. P. The Yin and Yang of the H-Channel and Its Role in Epilepsy. Epilepsy Curr.4, 3-6 (2004).

[65] Ludwig, A. et al. Absence epilepsy and sinus dysrhythmia in mice lacking the pacemaker channel HCN2. EMBO J.22, 216-224 (2003).

[66] Del Lungo, M. et al. Novel blockers of hyperpolarization-activated current with isoform selectivity in recombinant cells and native tissue. Br. J. Pharmacol.166, 602-616 (2012).

[67] van Luijtelaar, G., Berdiev, G., Schridde, U. \& Ruigt, G. The effects of the novel Ih channel blocker Org 34167 on ThalamoCortical Oscillations In Vivo. Sleep-Wake research in the Netherlands 17, 81-84 (2006).

[68] van Rijn, C. M. et al. WAG/Rij rats show a reduced expression of $\mathrm{CB}_{1}$ receptors in thalamic nuclei and respond to the $\mathrm{CB}_{1}$ receptor agonist, $\mathrm{R}(+)$ WIN55,212-2, with a reduced incidence of spike-wave discharges. Epilepsia51, 1511-21 (2010).

[69] Citraro, R. et al. Antiepileptic action of N-palmitoylethanolamine through CB1 and PPAR- $\alpha$ receptor activation in a genetic model of absence epilepsy. Neuropharmacology69, 115-126 (2013). 
[70] Yamamura, S. et al. ONO-2506 inhibits spike-wave discharges in a genetic animal model without affecting traditional convulsive tests via gliotransmission regulation. $\mathrm{Br}$. J. Pharmacol.168, 1088-100 (2013).

[71] Kohmann, D., Lüttjohann, A., Seidenbecher, T., Coulon, P. \& Pape, H.-C. Short-term depression of gap junctional coupling in reticular thalamic neurons of absence epileptic rats. J. Physiol.594, 5695710 (2016).

[72] Ates, N., Sahin, D. \& Ilbay, G. Theophylline, a methylxanthine derivative, suppresses absence epileptic seizures in WAG/Rij rats. Epilepsy Behav.5, 645-648 (2004).

[73] D'Alimonte, I. et al. Altered distribution and function of A2A adenosine receptors in the brain of WAG/Rij rats with genetic absence epilepsy, before and after appearance of the disease. Eur. J. Neurosci.30, 1023-1035 (2009).

[74] Gower, A. J., Hirsch, E., Boehrer, A., Noyer, M. \& Marescaux, C. Effects of levetiracetam, a novel antiepileptic drug, on convulsant activity in two genetic rat models of epilepsy. Epilepsy Res.22, 207-13 (1995).

[75] Bouwman, B. M. \& van Rijn, C. M. Effects of levetiracetam on spike and wave discharges in WAG/Rij rats. Seizure 13, 591-594 (2004).

[76] Verrotti, A. et al. Levetiracetam in absence epilepsy. Dev. Med. Child Neurol.50, 850-853 (2008).

[77] Elms, J. et al. Long-Term Valproate Treatment Increases Brain Neuropeptide Y Expression and Decreases Seizure Expression in a Genetic Rat Model of Absence Epilepsy. PLoS One8, e73505 (2013).

[78] van Raay, L., Jovanovska, V., Morris, M. J. \& O’Brien, T. J. Focal administration of neuropeptide $\mathrm{Y}$ into the $\mathrm{S} 2$ somatosensory cortex maximally suppresses absence seizures in a genetic rat model. Epilepsia53, 477-84 (2012).

[79] Coulter, D. A., Huguenard, J. R. \& Prince, D. A. Characterization of ethosuximide reduction of low-threshold calcium current in thalamic neurons. Ann. Neurol.25, 582-593 (1989).

[80] Leresche, N. et al. On the action of the anti-absence drug ethosuximide in the rat and cat thalamus. J. Neurosci.18, 4842-53 (1998).

[81] Crunelli, V. \& Leresche, N. Block of Thalamic T-Type Ca2+ Channels by Ethosuximide Is Not the Whole Story. Epilepsy Curr.2, 53-56 (2002).

[82] Broicher, T. et al. T-current related effects of antiepileptic drugs and a $\mathrm{Ca} 2+$ channel antagonist on thalamic relay and local circuit interneurons in a rat model of absence epilepsy. Neuropharmacology53, 431-446 (2007).

[83] Greenhill, S. D., Morgan, N. H., Massey, P. V., Woodhall, G. L. \& Jones, R. S. G. Ethosuximide modifies network excitability in the rat entorhinal cortex via an increase in GABA release. Neuropharmacology62, 807-814 (2012).

[84] Fogerson, P. M. \& Huguenard, J. R. Tapping the Brakes: Cellular and Synaptic Mechanisms that Regulate Thalamic Oscillations. Neuron92, 687-704 (2016)

[85] Manning, J. P. A., Richards, D. A., Leresche, N., Crunelli, V. \& Bowery, N. G. Cortical-area specific block of genetically determined absence seizures by ethosuximide. Neuroscience $123,5-$ 9 (2004).

[86] Powell, K. L., Cain, S. M., Snutch, T. P. \& O’Brien, T. J. Low threshold T-type calcium channels as targets for novel epilepsy treatments. Br. J. Clin. Pharmacol.77, 729-39 (2014).

[87] Tringham, E. et al. T-type calcium channel blockers that attenuate thalamic burst firing and suppress absence seizures. Sci. Transl. Med.4, 121 ra19 (2012).

[88] Shipe, W. D. et al. Design, synthesis, and evaluation of a novel 4aminomethyl-4-fluoropiperidine as a T-type $\mathrm{Ca} 2+$ channel antagonist. J. Med. Chem.51, 3692-5 (2008).

[89] Ngomba, R. T. et al. Metabotropic glutamate receptors in the thalamocortical network: Strategic targets for the treatment of absence epilepsy. Epilepsia52, 1211-1222 (2011).

[90] Nicoletti, F. et al. Metabotropic glutamate receptors: From the workbench to the bedside. Neuropharmacology60, 1017-1041 (2011).

[91] Moldrich, R. X., Chapman, A. G., De Sarro, G. \& Meldrum, B. S. Glutamate metabotropic receptors as targets for drug therapy in epilepsy. Eur. J. Pharmacol.476, 3-16 (2003).
[92] Conn, P. J. \& Pin, J.-P. Pharmacology and Functions of Metabotropic Glutamate Receptors. Annu. Rev. Pharmacol. Toxicol.37, 205-237 (1997).

[93] Hermans, E. \& Challiss, R. A. Structural, signalling and regulatory properties of the group I metabotropic glutamate receptors: prototypic family C G-protein-coupled receptors. Biochem. J.359, 465-84 (2001).

[94] Ngomba, R. T. et al. Protective role for type-1 metabotropic glutamate receptors against spike and wave discharges in the WAG/Rij rat model of absence epilepsy. Neuropharmacology60, 1281-1291 (2011).

[95] D'Amore, V. et al. Potentiation of mGlu5 receptors with the novel enhancer, VU0360172, reduces spontaneous absence seizures in WAG/Rij rats. Neuropharmacology66, 330-338 (2013).

[96] D'Amore, V. et al. Head-to head comparison of mGlu1 and mGlu5 receptor activation in chronic treatment of absence epilepsy in WAG/Rij rats. Neuropharmacology85, 91-103 (2014).

[97] Moldrich, R. X. et al. Anti-epileptic activity of group II metabotropic glutamate receptor agonists (-)-2-oxa-4aminobicyclo[3.1.0]hexane-4,6-dicarboxylate (LY379268) and (-) 2-thia-4-aminobicyclo[3.1.0]hexane-4,6-dicarboxylate (LY389795). Neuropharmacology41, 8-18 (2001).

[98] Kyuyoung, C. L. \& Huguenard, J. R. Modulation of short-term plasticity in the corticothalamic circuit by group III metabotropic glutamate receptors. J. Neurosci.34, 675-87 (2014).

[99] Snead, O. C., Banerjee, P. K., Burnham, M. \& Hampson, D. Modulation of absence seizures by the GABA(A) receptor: a critical rolefor metabotropic glutamate receptor 4 (mGluR4). $J$. Neurosci.20, 6218-24 (2000).

[100] Ngomba, R. T. et al. Positive allosteric modulation of metabotropic glutamate 4 (mGlu4) receptors enhances spontaneous and evoked absence seizures. Neuropharmacology54, 344-54 (2008).

[101] Ellens, D. J. et al. Development of spike-wave seizures in C3H/HeJ mice. Epilepsy Res.85, 53-9 (2009).

[102] Semple, B. D., Blomgren, K., Gimlin, K., Ferriero, D. M. \& NobleHaeusslein, L. J. Brain development in rodents and humans: Identifying benchmarks of maturation and vulnerability to injury across species. Prog. Neurobiol.106-107, 1-16 (2013).

[103] van der Bourg, A. et al. Layer-Specific Refinement of Sensory Coding in Developing Mouse Barrel Cortex. Cereb. Cortex (2016). doi:10.1093/cercor/bhw280

[104] Mishra, A. M. et al.Increased resting functional connectivity in spike-wave epilepsy in WAG/Rij rats. Epilepsia54, 1214-22 (2013).

[105] Chahboune, H. et al. DTI abnormalities in anterior corpus callosum of rats with spike-wave epilepsy. Neuroimage47, 459-466 (2009).

[106] Blumenfeld, H. et al. Early treatment suppresses the development of spike-wave epilepsy in a rat model. Epilepsia49, 400-409 (2008).

[107] Sarkisova, K. Y., Kuznetsova, G. D., Kulikov, M. A. \& van Luijtelaar, G. Spike-wave discharges are necessary for the expression of behavioral depression-like symptoms. Epilepsia51, 146-60 (2010).

[108] Russo, E. et al. Vigabatrin has antiepileptogenic and antidepressant effects in an animal model of epilepsy and depression comorbidity. Behav. Brain Res.225, 373-6 (2011).

[109] D'Amore, V. et al. The anti-absence effect of mGlu5 receptor amplification with VU0360172 is maintained during and after antiepileptogenesis. Pharmacol. Biochem. Behav.146, 50-59 (2016).

[110] Dezsi, G. et al. Ethosuximide reduces epileptogenesis and behavioral comorbidity in the GAERS model of genetic generalized epilepsy. Epilepsia54, 635-43 (2013).

[111] Citraro, R. et al. Perampanel effects in the WAG/Rij rat model of epileptogenesis, absence epilepsy, and comorbid depressive-like behavior. Epilepsia 231-238 (2016). doi:10.1111/epi.13629

[112] Depaulis, A. \& van Luijtelaar, G. Genetic models of absence epilepsy in the rat. in Models of Seizures and Epilepsy (eds. Pitkänen, A., Schwartkroin, P. \& Moshé, M.) 233-248 (2006).

[113] Bouwman, B. M. et al.The effects of vigabatrin on spike and wave discharges in WAG/Rij rats. Epilepsy Res.76, 34-40 (2007).

[114] Citraro, R., Leo, A., Constanti, A., Russo, E. \& De Sarro, G. mTOR pathway inhibition as a new therapeutic strategy in epilepsy and epileptogenesis. Pharmacol. Res.107, 333-343 (2016).

[115] Kovács, Z., Czurkó, A., Kékesi, K. A. \& Juhász, G. Neonata tricyclic antidepressant clomipramine treatment reduces the spike- 
wave discharge activity of the adult WAG/Rij rat. Brain Res. Bull.89, 102-7 (2012).

[116] Saillet, S. et al. Manipulating the epileptic brain using stimulation: a review of experimental and clinical studies. Epileptic Disord.11, 100-12 (2009).

[117] Kahane, P. \& Depaulis, A. Deep brain stimulation in epilepsy: what is next? Curr. Opin. Neurol.23, 177-182 (2010).

[118] Loddenkemper, T. et al. Deep brain stimulation in epilepsy. J. Clin. Neurophysiol.18, 514-32 (2001).

[119] Fisher, R. et al. Electrical stimulation of the anterior nucleus of thalamus for treatment of refractory epilepsy. Epilepsia51, 899-908 (2010).

[120] Vercueil, L. et al. High-frequency stimulation of the subthalamic nucleus suppresses absence seizures in the rat: comparison with neurotoxic lesions. Epilepsy Res.31, 39-46 (1998).

[121] Depaulis, A., Vergnes, M. \& Marescaux, C. Endogenous control of epilepsy: The nigral inhibitory system. Prog. Neurobiol.42, 33-52 (1994).

[122] Deransart, C. \& Depaulis, A. The control of seizures by the basal ganglia? A review of experimental data. Epileptic Disord.4 Suppl 3, S61-72 (2002).

[123] Feddersen, B. et al. Controlling seizures is not controlling epilepsy: a parametric study of deep brain stimulation for epilepsy. Neurobiol. Dis.27, 292-300 (2007).

[124] Kossoff, E. H. et al. Effect of an external responsive neurostimulator on seizures and electrographic discharges during subdural electrode monitoring. Epilepsia45, 1560-7 (2004).

[125] Osorio, I. et al. Automated seizure abatement in humans using electrical stimulation. Ann. Neurol.57, 258-68 (2005).

[126] Nelson, T. S. et al. Exploring the tolerability of spatiotemporally complex electrical stimulation paradigms. Epilepsy Res.96, 267-75 (2011).

[127] Huang, Z., Walker, M. C. \& Shah, M. M. Loss of dendritic HCN1 subunits enhances cortical excitability and epileptogenesis. $J$. Neurosci.29, 10979-10988 (2009).

[128] Huang, L. \& van Luijtelaar, G. The effects of responsive and scheduled subicular high frequency stimulation in the intrahippocampal kainic acid seizure model. Epilepsy Res.106, 326-37 (2013).

[129] Li, X., Ouyang, G. \& Richards, D. A. Predictability analysis of absence seizures with permutation entropy. Epilepsy Res.77, 70-4 (2007).

[130] Saillet, S. et al. Neural adaptation to responsive stimulation: a comparison of auditory and deep brain stimulation in a rat model of absence epilepsy. Brain Stimul.6, 241-7 (2013).

[131] Lüttjohann, A., Schoffelen, J.-M. \& van Luijtelaar, G. Termination of ongoing spike-wave discharges investigated by cortico-thalamic network analyses. Neurobiol. Dis.70, 127-37 (2014).

[132] Paz, J. T., Chavez, M., Saillet, S., Deniau, J.-M. \& Charpier, S. Activity of ventral medial thalamic neurons during absence seizures and modulation of cortical paroxysms by the nigrothalamic pathway. J. Neurosci.27, 929-41 (2007).

[133] Blik, V. Electric stimulation of the tuberomamillary nucleus affects epileptic activity and sleep-wake cycle in a genetic absence epilepsy model. Epilepsy Res.109, 119-125 (2015).

[134] van Heukelum, S., Kelderhuis, J., Janssen, P., van Luijtelaar, G. \& Lüttjohann, A. Timing of high-frequency cortical stimulation in a genetic absence model. Neuroscience324, 191-201 (2016).

[135] Cope, D. W. et al. Enhanced tonic GABA A inhibition in typical absence epilepsy. Nat. Med.15, 1392-1398 (2009).

[136] Lüttjohann, A., Schoffelen, J.-M. \& van Luijtelaar, G. Peri-ictal network dynamics of spike-wave discharges: phase and spectral characteristics. Exp. Neurol.239, 235-47 (2013).

[137] Sysoeva, M. V, Lüttjohann, A., van Luijtelaar, G. \& Sysoev, I. V. Dynamics of directional coupling underlying spike-wave discharges. Neuroscience314, 75-89 (2016).

[138] van Luijtelaar, G. et al. Methods of automated absence seizure detection, interference by stimulation, and possibilities for prediction in genetic absence models. J. Neurosci. Methods260, 144-58 (2016)

[139] Maxsimenko, V. et al. Absence Seizure Control by a Brain Computer Interface. Sci. Reports, Accept. Publ. (2017).

[140] Deisseroth, K. Optogenetics. Nat. Methods8, 26-29 (2011).

[141] Kros, L. et al.Cerebellar output controls generalized spike-andwave discharge occurrence. Ann. Neurol.77, 1027-49 (2015).
[142] Sorokin, J. M. et al. Bidirectional Control of Generalized Epilepsy Networks via Rapid Real-Time Switching of Firing Mode. Neuron93, 194-210 (2017).

[143] Berényi, A., Belluscio, M., Mao, D. \& Buzsáki, G. Closed-loop control of epilepsy by transcranial electrical stimulation. Science337, 735-7 (2012).

[144] San-Juan, D. et al. Transcranial direct current stimulation in epilepsy. Brain Stimul.8, 455-464 (2015).

[145] Lefaucheur, J.-P. et al. Evidence-based guidelines on the therapeutic use of transcranial direct current stimulation (tDCS). Clin. Neurophysiol.128, 56-92 (2016).

[146] San-Juan, D. et al. Transcranial Direct Current Stimulation in Mesial Temporal Lobe Epilepsy and Hippocampal Sclerosis. Brain Stimul. (2016). doi:10.1016/j.brs.2016.08.013

[147] Boggio, P. S. et al.Effects of transcranial direct current stimulation on working memory in patients with Parkinson's disease. J. Neurol. Sci.249, 31-38 (2006).

[148] Das, S., Holland, P., Frens, M. A. \& Donchin, O. Impact of Transcranial Direct Current Stimulation (tDCS) on Neuronal Functions. Front. Neurosci.10, 550 (2016).

[149] Nitsche, M. A. \& Paulus, W. Transcranial direct current stimulation--update 2011. Restor. Neurol. Neurosci.29, 463-92 (2011).

[150] Stagg, C. J. \& Nitsche, M. A. Physiological Basis of Transcranial Direct Current Stimulation. Neurosci.17, 37-53 (2011).

[151] Zobeiri, M. \& van Luijtelaar, G. Noninvasive transcranial direct current stimulation in a genetic absence model. Epilepsy Behav.26, 42-50 (2013).

[152] Nitsche, M. A. et al. Transcranial direct current stimulation: State of the art 2008. Brain Stimul1, 206-223 (2008).

[153] Liebetanz, D. et al. Anticonvulsant effects of transcranial directcurrent stimulation (tDCS) in the rat cortical ramp model of focal epilepsy. Epilepsia47, 1216-1224 (2006).

[154] Dhamne, S. C. et al. Acute seizure suppression by transcranial direct current stimulation in rats. Ann. Clin. Transl. Neurol.2, 84356 (2015).

[155] Kamida, T. et al. Transcranial direct current stimulation decreases convulsions and spatial memory deficits following pilocarpineinduced status epilepticus in immature rats. Behav. Brain Res.217, 99-103 (2011)

[156] Monte-Silva, K., Kuo, M.-F., Liebetanz, D., Paulus, W. \& Nitsche, M. a. Shaping the optimal repetition interval for cathodal transcranial direct current stimulation (tDCS). J. Neurophysiol.103, 1735-1740 (2010)

[157] Paulus, W. Outlasting excitability shifts induced by direct current stimulation of the human brain. Suppl. Clin. Neurophysiol.57, 70814 (2004).

[158] Cirillo, G. et al. Neurobiological after-effects of non-invasive brain stimulation. Brain Stimul.10, 1-18 (2017).

[159] Wiegand, A., Nieratschker, V. \& Plewnia, C. Genetic Modulation of Transcranial Direct Current Stimulation Effects on Cognition. Front. Hum. Neurosci.10, 1-7 (2016).

[160] Nitsche, M. a \& Paulus, W. Excitability changes induced in the human motor cortex by weak transcranial direct current stimulation. J. Physiol.527 Pt 3, 633-639 (2000).

[161] Nitsche, M. a et al. Pharmacological modulation of cortical excitability shifts induced by transcranial direct current stimulation in humans. J. Physiol.553, 293-301 (2003).

[162] Mielke, D. et al. Cathodal transcranial direct current stimulation induces regional, long-lasting reductions of cortical blood flow in rats. Neurol. Res.35, 1029-37 (2013).

[163] Godlevsky, L. S. et al. Influence of transcranial magnetic stimulation on spike-wave discharges in a genetic model of absence epilepsy. Indian J. Exp. Biol.44, 949-54 (2006).

[164] Scicchitano, F., van Rijn, C. M. \& van Luijtelaar, G. Unilateral and Bilateral Cortical Resection: Effects on Spike-Wave Discharges in a Genetic Absence Epilepsy Model. PLoS One10, e0133594 (2015).

[165] Régis, J. et al. Epilepsy related to hypothalamic hamartomas: surgical management with special reference to gamma knife surgery. Childs. Nerv. Syst.22, 881-95 (2006).

[166] Romanelli, P. \& Anschel, D. J. Radiosurgery for epilepsy. Lancet Neurol.5, 613-620 (2006).

[167] Sims, E. et al.Stereotactically delivered cranial radiation therapy: a ten-year experience of linac-based radiosurgery in the UK. Clin. Oncol. (R. Coll. Radiol).11, 303-20 (1999). 
[168] Studer, F. et al. Synchrotron X-ray microbeams: A promising tool for drug-resistant epilepsy treatment. Phys. Medica31, 607-614 (2015).

[169] Slatkin, D. N., Spanne, P., Dilmanian, F. A., Gebbers, J. O. \& Laissue, J. A. Subacute neuropathological effects of microplanar beams of x-rays from a synchrotron wiggler. Proc. Natl. Acad. Sci. U. S. A.92, 8783-7 (1995).

[170] Laissue, J. A. et al. The weanling piglet cerebellum: a surrogate for tolerance to MRT (microbeam radiation therapy) in pediatric neurooncology. Proc. SPIE4508, 65-73 (2001).

[171] Prayson, R. A. \& Yoder, B. J. Clinicopathologic findings in mesial temporal sclerosis treated with gamma knife radiotherapy. Ann. Diagn. Pathol.11, 22-6 (2007).

[172] Rockstroh, B. et al. Cortical self-regulation in patients with epilepsies. Epilepsy Res. 14, 63-72 (1993).

[173] Sterman, M. B. \& Egner, T. Foundation and practice of neurofeedback for the treatment of epilepsy. Appl. Psychophysiol. Biofeedback31, 21-35 (2006).
[174] Zhao, L., Wu, W., Liang, Z. \& Hu, G. Changes in EEG measurements in intractable epilepsy patients with neurofeedback training. Prog. Nat. Sci.19, 1509-1514 (2009).

[175] Osterhagen, L., Breteler, M. \& van Luijtelaar, G. Does arousal interfere with operant conditioning of spike-wave discharges in genetic epileptic rats? Epilepsy Res.90, 75-82 (2010).

[176] Liu, L. et al. The Mechanism of Carbamazepine Aggravation of Absence Seizures. J. Pharmacol. Exp. Ther.319, 790-798 (2006).

[177] D'Amore, V., Von Randow, C., Nicoletti, F., Ngomba, R. T. \& Van Luijtelaar, G. Anti-absence activity of mGlu1 and mGlu5 receptor enhancers and their interaction with a GABA reuptake inhibitor: Effect of local infusions in the somatosensory cortex and thalamus. Epilepsia56, 1141-1151 (2015).

[178] van Rijn, C. M., Weyn Banningh, E. W. \& Coenen, A. M. Effects of lamotrigine on absence seizures in rats. Pol. J. Pharmacol.46, 467-70 (1994) 